\title{
AVALIAÇÃO DA CONCENTRAÇÃO E COMPOSIÇÃO INORGÂNICA DO MATERIAL PARTICULADO COLETADO NO ESTADO DO RIO DE JANEIRO
}

\author{
Karmel Beringui ${ }^{a}$, Maria Fernanda C. Quijano ${ }^{a}$, Elizanne P. S. Justo ${ }^{a}$, Luciana Maria Baptista Venturaa ${ }^{\text {ab }}$ e Adriana \\ Gioda $^{a, *, D}$ \\ aDepartamento de Química, Pontifícia Universidade Católica do Rio de Janeiro, 22451-900 Rio de Janeiro - RJ, Brasil \\ 'Instituto Estadual do Ambiente, 20081-312 Rio de Janeiro - RJ, Brasil
}

Recebido em 21/11/2020; aceito em 28/01/2021; publicado na web em 18/02/2021

\begin{abstract}
ASSESSMENT OF THE CONCENTRATION AND INORGANIC COMPOSITION OF PARTICULATE MATTER COLLECTED IN THE STATE OF RIO DE JANEIRO. Cities urbanization and modernization increase emission sources, contributing to particulate matter (PM) composition heterogeneity and enhance the risk to human health and environment. This paper intends to survey the studies on particulate matter carried out in the state of Rio de Janeiro. The sampling of PM is generally made using Hi-Vol samplers to collect particles in fiberglass filter during $24 \mathrm{~h}$ every 6 days. Spectrometric techniques are used for elemental determination and ion chromatography for water-soluble species. The Environmental State Institute (INEA) is responsible for air quality monitoring in RJ. After 30 years, air quality standards have become more stringent and have included new pollutants. The highest PM concentrations were found in urban and industrial sites and the lowest in places away from urban activities or near the coast. Over the years, PM concentrations near steel complexes reduced even below the limits and varied at other places, remaining above the limits. Nitrate and sulfate were the main ionic compounds, and $\mathrm{Fe}, \mathrm{Al}$ and $\mathrm{Zn}$ were the major elements in PM samples. It was also found $\mathrm{Ni}, \mathrm{V}$, $\mathrm{Cd}, \mathrm{Pb}$ and $\mathrm{Cu}$. Although air quality monitoring is efficient, it still needs to be improved to help reduce the environmental impact.
\end{abstract}

Keywords: atmospheric pollution; particulate matter; chemical composition.

\section{INTRODUÇÃO}

O material particulado (MP) é formado por partículas líquidas ou sólidas suspensas no ar que apresentem diâmetro de até $100 \mu \mathrm{m} .{ }^{1}$ O termo aerossol é utilizado para se referir à suspensão coloidal de líquidos ou sólidos em um gás. Porém, no âmbito da avaliação da qualidade do ar, o termo material particulado é mais adequado, pois se refere apenas às partículas suspensas.

A totalidade do particulado suspenso no ar é denominado Partículas Totais em Suspensão (PTS), mas o MP pode ser classificado de acordo com os diâmetros aerodinâmicos dos sólidos. Os núcleos de Aitken, também denominados partículas ultrafinas ou nanopartículas $\left(\mathrm{MP}_{0,1}\right)$, são aquelas com diâmetros menores que $0,1 \mu \mathrm{m}$. Os sólidos que apresentam diâmetro menor que 2,5 $\mu \mathrm{m}$ formam o $\mathrm{MP}_{2,5} \mathrm{e}$ correspondem à fração fina do material particulado. As partículas com diâmetro menor que $10 \mu \mathrm{m}$ formam o $\mathrm{MP}_{10}$, enquanto aquelas de diâmetro entre 2,5 e $10 \mu \mathrm{m}$ correspondem à fração grossa do material particulado. ${ }^{2-6}$

A poluição causada pelo MP é considerada um dos principais problemas ambientais nas últimas décadas. Devido à importância desse poluente, suas concentrações podem ser utilizadas para avaliar a qualidade do ar de uma determinada região. ${ }^{7-9}$ Para enfrentar o desafio de combater a poluição ambiental, muitos estudos buscaram compreender sua formação, composição e transporte, entre outros fatores que permitiram estipular limites de qualidade do ar. Uma vez estabelecidas as características intrínsecas das partículas através de estudos realizados a partir da década de 1980, focaram-se as pesquisas na avaliação dos efeitos sobre a saúde humana, o ecossistema e as mudanças climáticas. ${ }^{10,11}$

A partir da década de 1990, alguns estudos buscaram avaliar os impactos do MP na saúde humana, embora a fração majoritária das pesquisas tenha evoluído para a caracterização química e o impacto

*e-mail: agioda@puc-rio.br sobre o clima. ${ }^{10}$ As partículas suspensas atuam em importantes processos climáticos, como: i) participação na formação de nuvens, pois atuam como núcleos de condensação, o que conduz à precipitação pluviométrica; ii) contribuição para o albedo terrestre, absorvendo ou refletindo a radiação incidente na superfície do planeta; e iii) atuação nas trocas oceano-troposfera através do spray marinho e ressuspensão do solo. $3,7,10,12-14$

O MP pode advir de diferentes fontes de emissão, sejam elas naturais (spray marinho, queimadas naturais de florestas, emissões vulcânicas, emissões da vegetação e tempestades de areia oriundas de desertos) ou antropogênicas (emissões veiculares, queima de biomassa ou combustível e atividades industriais). O MP pode ter origem primária, quando diretamente emitido para a atmosfera, ou origem secundária, quando os poluentes primários reagem, produzindo novas substânticas. ${ }^{3,8,10}$ Existe a tendência das partículas primárias formarem a fração grossa do material particulado, pois são produzidas pela fragmentação mecânica das maiores; enquanto as partículas secundárias compõem, principalmente, a fração mais fina, pois são formadas por processos de nucleação e condensação seguidos de reações químicas. ${ }^{3,15}$

As partículas mais grossas podem ser removidas a partir da atmosfera por deposição seca derivada da ação da gravidade. Desta forma, em virtude da maior massa e velocidade de queda, a deposição ocorre próxima às fontes de emissão. As partículas mais finas, que são removidas, principalmente, pela precipitação pluviométrica, apresentam maior tempo de residência na atmosfera e, portanto, podem ser depositadas em locais distantes da fonte de emissão. ${ }^{12,14,16}$ A deposição úmida, principal processo de remoção das partículas da atmosfera, pode ocorrer por meio de dois processos: i) rainout ou in-cloud, que consiste na formação de nuvens por meio da nucleação de partículas finas; ii) e wahsout ou below-cloud que decorre da ação das gotas de chuva que carreiam as partículas suspensas abaixo das nuvens, removendo-as da atmosfera. ${ }^{15}$

A crescente preocupação suscitada pela poluição atmosférica deve-se aos danos que os poluentes podem causar à saúde humana, 
principalmente num cenário de elevação contínua das emissões e da expansão da urbanização. ${ }^{17-19}$ Essa preocupação, entretanto, não é recente e está registrada na história para épocas mais antigas. Existem, por exemplo, registros de protestos populares contra o uso de carvão desde a Idade Média no Reino Unido, enquanto em Paris houve proibição da emissão de fumos nauseantes já no século XIV. A intensificação da utilização do carvão após a Revolução Industrial deu destaque a poluição atmosférica. Há registros de diversos casos de nevoeiros sulfurosos em Londres desde o século XVII, o que culminou na elaboração de medidas de controle da poluição do ar no século XIX. ${ }^{3}$ Um dos episódios mais importantes de poluição atmosférica ocorreu em Londres em 1952 (The Big Smoke), quando um nevoeiro escuro se espalhou pela cidade e as condições climáticas dificultaram sua dispersão. ${ }^{20}$ Durante o nevoeiro foram registradas 4.000 mortes diretamente relacionadas à exposição às partículas e 100.000 casos de doenças relacionadas ao episódio. ${ }^{21}$ Episódios semelhantes ocorreram em Donora e Nova York, nos EUA. A partir desses eventos, foram elaboradas legislações mais rigorosas para o controle da poluição atmosférica. Essas leis são revisadas periodicamente a fim de garantir a qualidade do ar. Associado às ações de controle da poluição, o avanço tecnológico contribuiu para melhoria da qualidade do ar. ${ }^{22-24}$

Apesar da preocupação com a qualidade do ar e os avanços obtidos nas últimas décadas, $91 \%$ da população mundial vive em cidades nas quais a concentração de $\mathrm{MP}_{2,5}$ ultrapassa o limite anual $\left(10 \mu \mathrm{g} \mathrm{m}^{-3}\right)$ recomendado pela Organização Mundial da Saúde (OMS). Como resultado, em torno de 4,2 milhões de pessoas morrem anualmente em decorrência da exposição à poluição atmosférica. ${ }^{25} \mathrm{~A}$ medida que o diâmetro da partícula se reduz, o poder de penetração no sistema respiratório aumenta, podendo atingir os alvéolos pulmonares onde os componentes do MP poderão ser transferidos para a corrente sanguínea. ${ }^{5,26-28}$

Nas últimas décadas, estudos voltados para avaliação dos impactos do MP à saúde humana são predominantes. Esses estudos buscam verificar a associação entre a exposição às partículas e o desenvolvimento de diversas doenças, bem como avaliar o impacto causado aos diferentes grupos da população, como crianças, jovens, idosos e profissionais que trabalham expostos à poluição do $a^{28-32}$ Algumas pesquisas conduzidas em diferentes partes do mundo revelam que a exposição temporária ou contínua ao MP pode ser associada às doenças respiratórias e cardiovasculares e ao câncer. ${ }^{5,7,18,28,33-36} \mathrm{As}$ crianças podem ser mais gravemente afetadas, pois já foi verificado que exposição materna a altos níveis de MP pode levar ao baixo peso ao nascer, prematuridade, aumento da mortalidade de fetos, além do comprometimento do desenvolvimento pulmonar, incluindo deficits irreversíveis. ${ }^{537-39}$ Juntamente com as crianças, os idosos completam o grupo dos mais suscetíveis às doenças respiratórias causadas pela exposição ao MP, pois na infância o sistema imunológico não está totalmente desenvolvido e nos idosos já está debilitado. ${ }^{5,10}$

Embora as partículas finas despertem maior atenção devido aos efeitos sobre a saúde humana, as partículas grossas podem causar danos aos ecossistemas, uma vez que seus componentes podem ser absorvidos pelo solo ou diretamente pelas plantas..$^{40,41} \mathrm{O}$ impacto ao meio ambiente depende da composição e da superfície sobre a qual o MP é depositado, uma vez que seus componentes podem atuar como nutrientes ou poluentes. ${ }^{7,16}$ Em um ecossistema, os organismos vivos estão em constante interação com elementos abióticos e alguns estudos revelam que plantas podem atuar como filtros de poluição, uma vez que removem poluentes do meio. ${ }^{41-44}$ Entretanto, essas substâncias, quando absorvidas pelas plantas, podem causar danos como o bloqueio dos estômatos, organelas responsáveis pelas trocas gasosas, ou comprometimento de processos fisiológicos, como a fotossíntese ou produção de proteínas. ${ }^{41}$
Além de alterar a composição do solo sobre o qual se deposita, o MP pode, ainda, contribuir para a acidificação do solo ou de ecossistemas aquáticos, podendo ainda provocar danos às construções e monumentos. ${ }^{14,45} \mathrm{~A}$ mudança no $\mathrm{pH}$ pode ser prejudicial às espécies endêmicas de um dado habitat ou até mesmo levá-las à morte. ${ }^{46} \mathrm{~A}$ deposição ácida ocorre tanto por via úmida quanto por via seca. Pela via úmida, partículas contendo $\mathrm{SO}_{4}{ }^{2-}$ e $\mathrm{NO}_{3}^{-}$formam núcleos de condensação de nuvens, originando a chuva ácida por meio da reação entre esses íons e moléculas de água. A acidificação por via seca ocorre quando partículas contendo íons de ácidos fortes se depositam em superfícies com alto percentual de umidade, o que provoca a formação dos ácidos correspondentes. ${ }^{45}$

A heterogeneidade na composição e a distribuição espacial do MP dependem de variáveis meteorológicas, topográficas, das fontes de emissão e da morfologia das partículas. ${ }^{5,7,17}$ A heterogeneidade é mais acentuada próximo às fontes de emissão, pois à medida que há o transporte para longe das fontes, a tendência é uma maior homogeneidade devido a processos atmosféricos. ${ }^{10} \mathrm{O}$ maior tempo de residência das partículas finas na atmosfera as tornam mais suscetíveis às mudanças na composição ao longo do transporte, o que pode dificultar a atribuição de fontes. ${ }^{10,47}$

Os principais componentes do MP são os compostos de carbono, em suas diferentes formas (orgânica, inorgânica e elementar). ${ }^{12}$ Além desses, estão presentes espécies solúveis em água, representando em torno de $30 \%$ da composição das partículas. ${ }^{48}$ Elementos metálicos e hidrocarbonetos policíclicos aromáticos (HPA) são, geralmente, encontrados em níveis traço no MP, e contribuem para o aumento da toxidade das partículas, tanto para a saúde humana quanto para o ecossistema. ${ }^{5,14,35,49}$ A fração fina do MP, principalmente, pode apresentar ainda outros componentes orgânicos tóxicos, porque no processo de formação dessas partículas os compostos orgânicos voláteis (COV) são transferidos da fase gasosa para a particulada e sofrem reações. Os COV são emitidos por fontes naturais, como as plantas, ou fontes antropogênicas, como a queima de combustível fóssil. ${ }^{10,50}$ Além das substâncias químicas, o material biológico também faz parte da composição do MP. As partículas biogênicas são formadas por fragmentos de células, pólen e esporos ${ }^{5,14}$

$\mathrm{O}$ estado do Rio de Janeiro foi o pioneiro a estabelecer o monitoramento da qualidade do ar em 1967 e, portanto, apresenta a maior série histórica de dados de monitoramento atmosférico, além da maior quantidade de poluentes monitorados por estação. ${ }^{51,52}$ O monitoramento atmosférico no estado é responsabilidade do Instituto Estadual do Ambiente (INEA), que possui 84 estações de monitoramento da qualidade do ar e, por meio do licenciamento ambiental, recebe dados de estações operadas por empresas com significativo potencial poluidor. ${ }^{53}$

A maioria dos estudos realizados no Rio de Janeiro relacionados à poluição do ar por MP segue as normas estabelecidas pela Associação Brasileiras de Normas e Técnicas (ABNT), que apresenta o mesmo procedimento recomendado pelas agências ambientais internacionais para a coleta de MP. Assim, as partículas são coletadas utilizando amostradores de grande volume (do inglês, high volume air sampler, Hi-Vol). Após tratamento químico, a composição elementar é determinada por técnicas como espectrometria de absorção atômica por chama (do inglês, Flame Atomic Absorption Spectrometery, FAAS), fluorescência de raio-X (do inglês, $X$-ray fluorescence, XRF), espectrometria de emissão óptica com plasma indutivamente acoplado (do inglês, Inductively Coupled Plasm Optical Emission Spectrometry, ICP OES) e espectrometria de massas com plasma indutivamente acoplado (do inglês, Inductively Coupled Plasm Mass Spectrometry, ICP-MS). A composição iônica tem sido determinada por cromatografia de íons (CI), a composição elementar de carbono através de um analisador total de carbono (do inglês, Total Organic 
Carbon Analyzer - TOC) e a concentração de HPA por cromatografia gasosa associada à espectrometria de massa (do inglês, Gas Chromatography - Mass Spectrometry, GC-MS). ${ }^{7,18,54-67}$

Considerando a importância do material particulado para a avaliação da qualidade do ar, este artigo tem como objetivo fazer uma revisão bibliográfica dos estudos sobre a concentração, tamanho e composição química de partículas (PTS, $\mathrm{MP}_{10}$ e $\mathrm{MP}_{2,5}$ ) coletadas no estado do Rio de Janeiro, desde que os estudos nessa área foram iniciados em 1981 até os estudos mais recentes referentes aos dados coletados até 2017.

\section{PADRÕES INTERNACIONAIS DE QUALIDADE DO AR}

Diante da importância do MP e seus efeitos à saúde humana e ao meio ambiente, algumas instituições internacionais estabelecem limites para a concentração diária e média anual de $\mathrm{MP}_{10}$ e $\mathrm{MP}_{2,5}$. A Organização Mundial da Saúde (OMS), com base em estudos epidemiológicos, faz orientações sobre padrões de qualidade do ar referentes aos poluentes que representam risco à saúde da população, visando diminuir seu impacto. Para o $\mathrm{MP}_{2,5}$, a OMS recomenda padrões de qualidade do ar para a fração fina, $25 \mu \mathrm{g} \mathrm{m}^{-3}$ e $10 \mu \mathrm{g} \mathrm{m}^{-3}$ para a concentração diária e média anual, respectivamente. ${ }^{68}$ Para a fração grossa do MP, os limites diário e anual são $50 \mu \mathrm{g} \mathrm{m}^{-3} \mathrm{e}$ $20 \mu \mathrm{g} \mathrm{m}{ }^{-3}$, respectivamente. ${ }^{68}$ A Agência de Proteção Ambiental do Estados Unidos (do inglês, United States Environmental Protection Agency USEPA) estabelece limites diários de $35 \mu \mathrm{g} \mathrm{m}^{-3}$ e $150 \mu \mathrm{g} \mathrm{m}^{-3}$ para $\mathrm{MP}_{2,5}$ e $\mathrm{MP}_{10}$, respectivamente. Não existe valor recomendado para a média anual de $\mathrm{MP}_{10}$, mas para $\mathrm{MP}_{2,5}$ o limite estabelecido é de $12 \mu \mathrm{g} \mathrm{m}^{-3} .{ }^{69} \mathrm{O}$ Diretório Geral do Meio Ambiente da União Européia (do inglês, Environment Directorate General of the European Commission - DG Environment) estabelece para $\mathrm{MP}_{2.5}$ apenas o limite anual de $25 \mu \mathrm{g} \mathrm{m}^{-3}$. Já para $\mathrm{MP}_{10}$ são estabelecidos limites diário de $50 \mu \mathrm{g} \mathrm{m}^{-3}$ e anual de $40 \mu \mathrm{g} \mathrm{m}^{-3} \cdot{ }^{70}$ Esses limites estabelecidos pelas mais importantes agências ambientais do mundo são utilizados como referência para a elaboração de padrões nacionais de qualidade do ar em diversos países.

A composição do MP é importante para estimar os impactos causados, por isso algumas agências internacionais inseriram em seus padrões de qualidade do ar limites para a concentração de algumas substâncias nas partículas. A USEPA estabelece limite de $0,5 \mu \mathrm{g} \mathrm{m}^{-3}$ para $\mathrm{Pb}$ e o DG Environment estabelece limites de $0,5 \mu \mathrm{g} \mathrm{m}^{-3}$ para $\mathrm{Pb}, 6 \mathrm{ng} \mathrm{m}^{-3}$ para As, $5 \mathrm{ng} \mathrm{m}^{-3}$ para Cd e $20 \mathrm{ng} \mathrm{m}^{-3}$ para Ni. Embora existam padrões de qualidade do ar para poucos elementos, muitos estudos foram realizados buscando fazer a caracterização química mais ampla das partículas.

\section{LEGISLAÇÃO BRASILEIRA}

No Brasil, a preocupação com a qualidade do ar iniciou a partir da década de 1970, em um período de intenso crescimento industrial. A primeira legislação brasileira que estabeleceu padrões de qualidade do ar no Brasil foi a Portaria Minter 231/1976, que considerava os poluentes: Partículas em Suspensão, $\mathrm{SO}_{2}, \mathrm{CO}$ e Oxidantes Fotoquímicos. Na década de 1980 ocorreu crescimento da frota automobilística, o que estimulou o Conselho Nacional do Meio Ambiente (CONAMA) a criar a Resolução CONAMA 18/1986 que visava o controle das emissões veiculares. Posteriormente surgiu a necessidade de um maior controle da poluição atmosférica, por isso em 1989 o CONAMA criou o Programa Nacional de Controle da Qualidade do Ar (PRONAR), por meio da Resolução 05/1989. O PRONAR visava o desenvolvimento sustentável por meio da elaboração de instrumentos de controles, tais como estabelecimento de limites de emissão, padrões de qualidade do ar e inventários de fontes de emissão. Após a criação do PRONAR, a portaria Minter 231/1976 foi revogada pela Resolução CONAMA 003/1990 que, além de manter os padrões já estabelecidos, incluía outros poluentes, considerando informações científicas mais recentes. Essa resolução estabeleceu padrões de qualidade do ar para PTS, $\mathrm{MP}_{10}$, $\mathrm{SO}_{2}, \mathrm{CO}, \mathrm{NO}_{2}$ e fumaça.

A Resolução 003/1990 considerava dois valores de concentração para cada poluente: i) padrão primário $\left(\mathrm{P} 1^{\circ}\right)$, acima do qual o poluente poderia causar risco à saúde e ii) padrão secundário $\left(\mathrm{P} 2^{\circ}\right)$, abaixo do qual são previstos efeitos mínimos à saúde e ao meio ambiente. Essa resolução vigorou por quase 30 anos sem revisão, embora estudos científicos já apontassem a importância do monitoramento de outros poluentes, além da redução dos limites de emissão. Apesar das evidências científicas, os padrões que permaneceram em vigor por décadas no Brasil estavam muito defasados se comparados aos padrões recomendados pela OMS e estabelecidos pela USEPA. Com relação ao MP, a legislação brasileira recomendava o monitoramento de PTS e $\mathrm{MP}_{10}$ e considerava como padrões de qualidade do ar concentrações muito superiores aos dessas agências. Os documentos mais recentes da OMS e USEPA, que são de 2005, já incluíam $\mathrm{MP}_{2,5}$ e apresentavam concentrações para $\mathrm{MP}_{10}$ até três vezes menores do que a legislação brasileira.

A publicação de dados científicos e revisões feitas por agências ambientais internacionais com estabelecimento de limites mais restritivos estimularam a revisão da legislação brasileira. Após um longo período de elaboração, em 2018, a Resolução 003/1990 foi substituída pela resolução CONAMA 491/2018 que apresenta padrões mais restritivos e inclui novos poluentes, como o $\mathrm{MP}_{2,5}$ e $\mathrm{Pb}_{\text {em PTS }}$. $^{71,72}$ Esse documento foi elaborado com base nos valores de referência recomendados em 2005 pela OMS. Foram estabelecidos três padrões intermediários (PI) de qualidade do ar e um Padrão Final (PF), que devem ser adotados sequencialmente, sendo os PFs equivalentes aos valores sugeridos pela OMS. A criação dos PI foi necessária devido à grande diferença entre os padrões antigos e os padrões finais previstos na Resolução 491/2018. Tais valores visam permitir as agências ambientais estaduais e os responsáveis pelas emissões se adequarem aos novos padrões de qualidade do ar mais restritivos. A partir da data de promulgação da Resolução 491/2018 o PI-1 foi adotado e a progressão entre os PI até o PF deverá ocorrer de acordo com planos de controle de emissão elaborados pelas agências ambientais estaduais. Até o momento nenhuma delas divulgou o planejamento para fazer a progressão entre os PI nem o prazo para adoção do PF.

Com a atualização dos padrões de qualidade do ar, a legislação brasileira passou a apresentar limites para as três frações de MP. O guia da OMS de 2005 deixou de estabelecer limites para PTS, dessa forma, os valores para PTS não foram alterados na Resolução 491/2018. Os limites para $\mathrm{MP}_{10}$ sofreram grande redução (de $20 \%$ a $30 \%$ ), comparado ao PF. Essa defasagem entre os valores das duas resoluções pode ser atribuída ao longo tempo sem ocorrência de atualização dos padrões.

Embora exista uma lei que estabeleça padrões para a qualidade do ar, a rede nacional de monitoramento é bem reduzida. De acordo com o Instituto de Energia e Meio Ambiente (IEMA), em 2018 apenas 9 unidades federativas, dentre as 27 , apresentavam programas para monitoramento da qualidade do ar, que são gerenciados por órgãos estaduais, à exceção da Bahia, onde o monitoramento é realizado por empresas privadas. ${ }^{73}$ Além do número reduzido de estações de monitoramento, os dados emitidos pelas agências ambientais revelam que nem todos os padrões estabelecidos na lei são monitorados em todas as estações. Muitas apresentam descontinuidade no funcionamento, além da baixa representatividade dos dados, o que compromete o diagnóstico da poluição do ar. $^{51}$

A Tabela 1 apresenta os padrões de qualidade do ar estabelecidos pelas resoluções do CONAMA de 1990 e 2018. Na nova resolução 
verifica-se a inclusão de limites para $\mathrm{MP}_{2,5}$, partículas que representam maior risco a saúde devido ao seu maior poder de penetração no sistema respiratório e maior relação com emissões antropogênicas. Além disso, pode ser verificado que, pela primeira vez, a legislação considera a composição das partículas ao estabelecer limites de concentração de $\mathrm{Pb}$ nas PTS em áreas específicas, de acordo com as características das fontes de emissão. A necessidade de monitoramento desse parâmetro deve ser definida pelo órgão ambiental competente. A USEPA foi a agência pioneira em estabelecer padrões para a concentração de $\mathrm{Pb}$ no material particulado, estabelecendo, em 1978, a concentração de $1,5 \mu \mathrm{g} \mathrm{m}^{-3}$. Ao longo dos anos, o padrão para $\mathrm{Pb}$ foi revisado, chegando ao atual valor de $0,5 \mu \mathrm{g} \mathrm{m}^{-3}$, que foi usado pelo CONAMA como referência para a nova resolução sobre os padrões de qualidade do ar do Brasil.

\section{AMOSTRAGEM DE MATERIAL PARTICULADO}

\section{Locais de amostragem}

No estado do Rio de Janeiro já foram realizados estudos sobre a concentração e composição do MP em 28 cidades. . $^{11,13,54-56,58-67,74-85}$ Grande parte deles foram realizados na região metropolitana, principalmente na cidade do Rio de Janeiro e nos municípios da Baixada Fluminense. A Figura 1 apresenta a localização dos municípios do estado do Rio de Janeiro nos quais já foram realizados estudos sobre MP.

\section{Coleta de MP}

O INEA realiza o monitoramento atmosférico da concentração de gases como $\mathrm{SO}_{2}, \mathrm{NO}_{2}, \mathrm{O}_{2}, \mathrm{CO}$, de material particulado (PTS, $\mathrm{MP}_{10}$ e $\mathrm{MP}_{2,5}$ ) e alguns compostos orgânicos como benzeno, tolueno, etilbenzeno, meta, orto e para-xilenos e hidrocarbonetos totais. ${ }^{51}$ Há dois tipos de estações de monitoramento: i) automático, nas quais a amostragem e a análise ocorrem em tempo real, a cada 5 segundos; essa abordagem tem sido utilizada para $\mathrm{MP}_{10}, \mathrm{MP}_{2,5}, \mathrm{SO}_{2}, \mathrm{NO}, \mathrm{NO}_{2}$,
$\mathrm{CO}, \mathrm{O}_{3}$, benzeno/tolueno/etilbenzeno/xileno (BTEX) e Enxofre Reduzido Total (ERT); ii) manual ou semiautomático, aquelas nas quais depois de coletada, a amostra é levada para o laboratório, onde é analisada; essa abordagem pode ser aplicada para diversos poluentes atmosféricos, assim como o monitoramento automático, entretanto, o INEA usa apenas para Fumaça, PTS, $\mathrm{MP}_{10}$ e MP ${ }_{2,5}$. Após a validação dos dados de concentração de MP, os filtros contendo as partículas não são utilizados pelo INEA, de tal forma que podem ser disponibilizados para grupos de pesquisa interessados em fazer caracterização química do MP.

Alguns grupos de pesquisas possuem equipamentos similares aos utilizados pelo INEA, o que lhes permite coletar MP em áreas de interesse para seus estudos, inclusive naquelas em que não há estação de monitoramento da agência ambiental do estado. A amostragem do MP é feita utilizando amostradores de grande volume (Hi-Vol) seguindo os métodos padrões brasileiros (ABNT-NBR 9547 para PTS, ABNTNBR 13412 para $\mathrm{MP}_{10}$ e $\mathrm{PM}_{2,5}$ ) que estão de acordo com o método de detecção sugerido pela USEPA. Estes equipamentos aspiram o ar a uma vazão constante $\left(1,1-1,7 \mathrm{~m}^{3} \mathrm{~min}^{-1}\right)$, fazendo-o passar por uma entrada (inlet) que faz a seleção de tamanho das partículas a serem retidas em filtros de fibra de vidro, quartzo ou Teflon ${ }^{\circledR}$. As amostras são coletadas continuamente por $24 \mathrm{~h}$ a cada seis dias.

A massa de MP coletada é determinada por gravimetria, fazendo a pesagem dos filtros antes e após a amostragem em condições de umidade $(20-30 \% \pm 5 \%)$ e temperatura $\left(20-25{ }^{\circ} \mathrm{C} \pm 2{ }^{\circ} \mathrm{C}\right)$ controladas. Dividindo os dados de massa pelo produto da vazão e tempo de amostragem obtém-se a concentração em massa de partículas por volume de ar amostrado $\left(\mu \mathrm{g} \mathrm{m}^{-3}\right)$.

Uma outra forma de coletar o MP é utilizando um sistema com filtros empilhados (do inglês, stacked filter units, SFU), que consiste em um suporte para mais de um filtro, permitindo a coleta de diferentes tamanhos de partículas separadamente. Neste caso, são utilizadas membranas com diferentes porosidades para coletar o MP. A primeira membrana possui poros maiores para permitir a passagem das partículas menores, que serão retidas em membranas posteriores, com menor porosidade. Assim como o Hi-Vol, o SFU

Tabela 1. Padrões de Qualidade do ar da legislação brasileira (CONAMA)

\begin{tabular}{|c|c|c|c|c|c|c|c|}
\hline \multirow{2}{*}{$\begin{array}{l}\text { Poluentes } \\
\text { Atmosféricos }\end{array}$} & \multirow{2}{*}{ Período } & \multicolumn{4}{|c|}{ RE 491/2018 } & \multicolumn{2}{|c|}{ RE 003/1990 } \\
\hline & & PI-1 $\left(\mu \mathrm{g} \mathrm{m}^{-3}\right)$ & PI-2 $\left(\mu \mathrm{g} \mathrm{m}^{-3}\right)$ & PI-3 $\left(\mu \mathrm{g} \mathrm{m}^{-3}\right)$ & $\mathrm{PF}\left(\mu \mathrm{g} \mathrm{m}^{-3}\right)$ & $\mathrm{P} 1^{\circ}\left(\mu \mathrm{g} \mathrm{m}^{-3}\right)$ & $\mathrm{P} 2^{\circ}\left(\mu \mathrm{g} \mathrm{m}^{-3}\right)$ \\
\hline \multirow{2}{*}{ PTS } & $24 \mathrm{~h}$ & - & - & - & 240 & 240 & 150 \\
\hline & Anual $^{\mathrm{a}}$ & - & - & - & 80 & 80 & 60 \\
\hline \multirow{2}{*}{$\mathrm{MP}_{10}$} & $24 \mathrm{~h}$ & 120 & 100 & 75 & 50 & 150 & - \\
\hline & Anual $^{\mathrm{b}}$ & 40 & 35 & 30 & 20 & 50 & - \\
\hline \multirow{2}{*}{$\mathrm{MP}_{2,5}$} & $24 \mathrm{~h}$ & 60 & 50 & 37 & 25 & - & - \\
\hline & Anual $^{\mathrm{b}}$ & 20 & 17 & 15 & 10 & - & - \\
\hline \multirow{2}{*}{$\mathrm{NO}_{2}$} & $1 \mathrm{~h}$ & 260 & 240 & 220 & 200 & 320 & 190 \\
\hline & Anual $^{\mathrm{b}}$ & 60 & 50 & 45 & 40 & 100 & 100 \\
\hline \multirow{2}{*}{$\mathrm{SO}_{2}$} & $24 \mathrm{~h}$ & 125 & 50 & 30 & 20 & 365 & 100 \\
\hline & Anual $^{\mathrm{b}}$ & 40 & 30 & 20 & - & 80 & 40 \\
\hline \multirow{2}{*}{$\mathrm{CO}$} & $8 \mathrm{~h}^{\mathrm{c}}$ & - & - & - & $10.000^{\mathrm{e}}$ & $10.000^{\mathrm{e}}$ & - \\
\hline & $1 \mathrm{~h}^{\mathrm{c}}$ & - & - & - & - & $40.000^{\mathrm{f}}$ & - \\
\hline \multirow{2}{*}{$\mathrm{O}_{3}$} & $8 \mathrm{~h}^{\mathrm{c}}$ & 140 & 130 & 120 & 100 & - & - \\
\hline & $1 \mathrm{~h}^{\mathrm{c}}$ & - & - & - & - & 160 & - \\
\hline \multirow{2}{*}{ Fumaça } & $24 \mathrm{~h}$ & 120 & 100 & 75 & 50 & 150 & 100 \\
\hline & Anual $^{\mathrm{b}}$ & 40 & 35 & 30 & 20 & 60 & 40 \\
\hline $\mathrm{Pb}$ & Anual $^{\mathrm{d}}$ & - & - & - & 0,5 & - & - \\
\hline
\end{tabular}

${ }^{\mathrm{a}}$ Média geométrica anual; ${ }^{\mathrm{b}}$ Média aritmética anual; ${ }^{\mathrm{C}}$ Máxima média móvel diária; ${ }^{\mathrm{d}}$ Medido nas PTS; ${ }^{\mathrm{e}} 9 \mathrm{ppm} ;{ }^{\mathrm{f}} 35 \mathrm{ppm}$. 


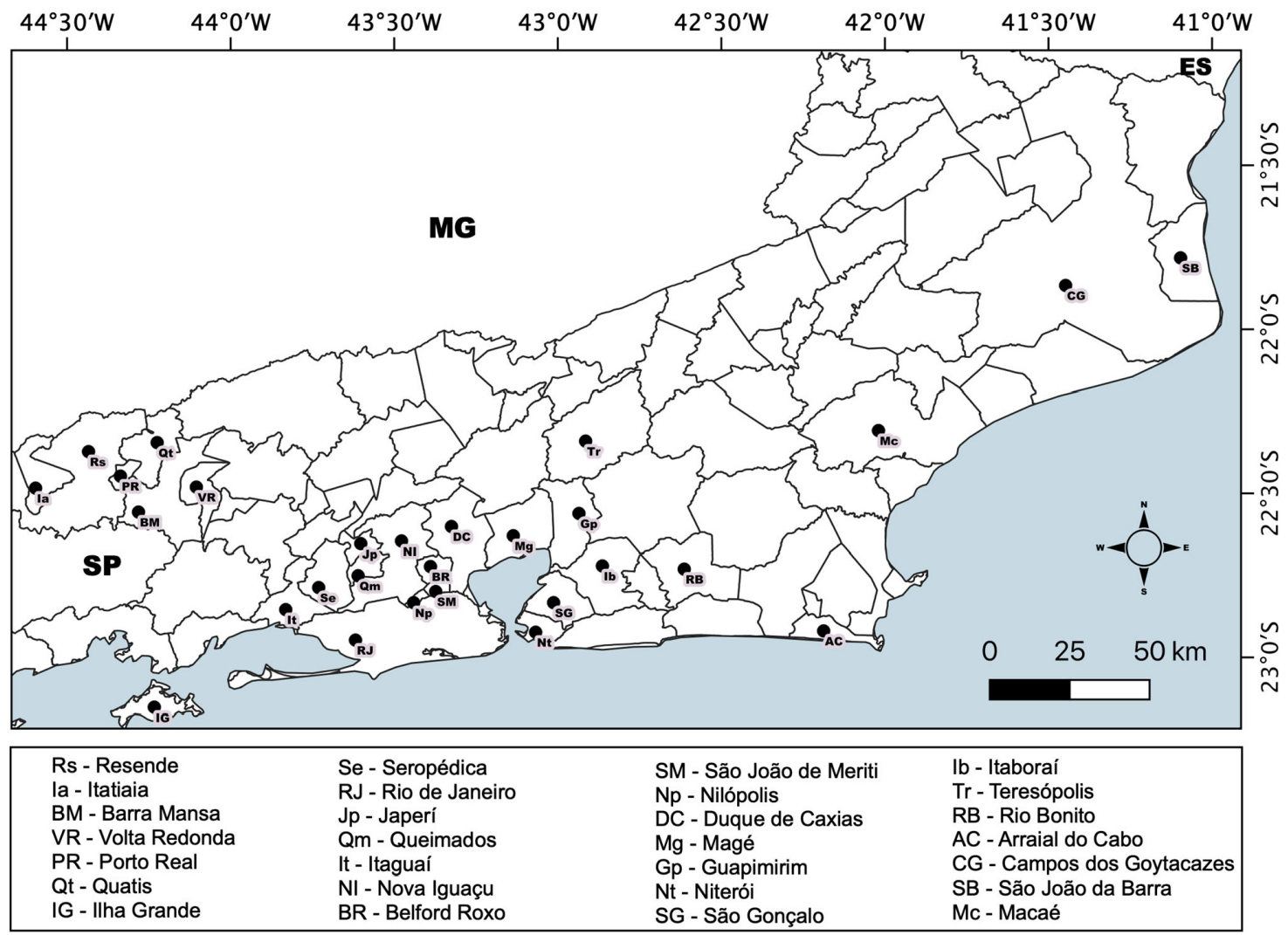

Figura 1. Mapa com a localização dos pontos de amostragem utilizados nos estudos sobre MP realizados no estado do Rio de Janeiro. Software QGIS, Fonte dos dados: Instituto Brasileiro de Geografia e Estatística - IBGE, Instituto de Pesquisa Econômica Aplicada - Ipea, IHO Sea Area

utiliza uma bomba para aspirar ar com vazão constante e tempo de amostragem determinado ${ }^{86}$ Esse tipo de amostragem permite obter a razão entre dois tamanhos de partículas e informará quais partículas contribuem mais para a concentração do MP. Além disso, alguns estudos usam a razão entre os tamanhos de partículas para caracterizar uma determinada região. ${ }^{65,66,87}$

\section{CONCENTRAÇÃO DE MATERIAL PARTICULADO}

\section{Resultados do primeiro diagnóstico da rede de monitoramento da qualidade do ar no Brasil}

O primeiro diagnóstico da rede de monitoramento da qualidade do ar no Brasil foi elaborado pelo Instituto de Energia e Meio Ambiente e publicado em 2018. ${ }^{51}$ Esse relatório teve por objetivos: i) divulgar as informações e os dados gerados pelas redes de monitoramento existentes em todas as unidades federativas brasileiras que estivesse sob responsabilidade do poder público ou privado; ii) usar tais informações para incentivar discussão sobre revisão do PRONAR; iii) identificar as dificuldades no monitoramento e propor alternativas para obtenção de recursos. Esse documento reuniu dados de monitoramento da qualidade do ar do Distrito Federal, Espírito Santo, Minas Gerais, Paraná, Rio de Janeiro, Bahia, São Paulo, Rio Grande do Sul e Sergipe.

Para o estado do Rio de Janeiro foram considerados os dados de material particulado (PTS e $\mathrm{MP}_{10}$ ), $\mathrm{SO}_{2}, \mathrm{NO}_{2}, \mathrm{O}_{3}$ e $\mathrm{CO}$ coletados pelo INEA entre 2000 e 2012 em 18 municípios do estado. A Tabela 1S (Material Suplementar) apresenta as estações do INEA que apresentaram dados de material particulado e as Tabelas $2 \mathrm{~S}$ e $3 \mathrm{~S}$ (Material Suplementar) apresentam as médias por município para PTS e $\mathrm{MP}_{10}$, respectivamente. As médias das concentrações das partículas foram calculadas usando apenas os dados considerados representativos.
Os resultados apresentados no diagnóstico mostram como em muitas estações houve descontinuidade de monitoramento ou dados que não são considerados representativos, o que consiste em um problema para a avaliação eficiente da qualidade do ar. Para os dois tamanhos de partículas os municípios do Rio de Janeiro e Volta Redonda foram os que apresentaram a séries de dados mais completas. Embora em Volta Redonda estejam instalados importantes empreendimentos industriais, foram encontradas menores concentrações de PTS e $\mathrm{MP}_{10}$ do que no Rio de Janeiro. São Gonçalo e Belford Roxo, municípios da Baixada Fluminense, apresentaram as maiores concentrações de PTS, todas elas acima do limite anual estabelecido pelo CONAMA. São João de Meriti e Nova Iguaçu, também na Baixada Fluminense, apresentaram as maiores concentrações de $\mathrm{MP}_{10}$. As menores concentrações de PTS e $\mathrm{MP}_{10}$ foram observadas nos munícipios do norte fluminense, no médio Paraíba (exceção de Volta Redonda), em Guapimirim, Itaboraí e Itaguaí.

Além da evidente defasagem da legislação brasileira, que permaneceu vigente entre 1990 e 2018, consta-se, pelo acima exposto, que houve pouco avanço no monitoramento da qualidade do ar no Brasil, mesmo no Rio de Janeiro, estado pioneiro no monitoramento atmosférico. As principais barreiras para esse avanço foram o baixo número de profissionais envolvidos, que resulta na cobertura precária do monitoramento, e a falta de recursos, que resulta na descontinuidade das medidas. O documento de 2018 expõe a pouca importância dada ao monitoramento da qualidade do ar pelos órgãos governamentais.

\section{Influência dos Jogos Olímpicos de 2016 na concentração de MP}

A cidade do Rio de Janeiro sediou os Jogos Olímpicos e Paraolímpicos de 2016 (Rio 2016), que ocorreram entre 5 de agosto e 
18 de setembro. ${ }^{88}$ Desde as Olimpíadas de Sidney em 2000, o Comitê Olímpico Internacional (COI) demonstrou maior preocupação com a qualidade do ar, por isso, o monitoramento de alguns poluentes atmosféricos, como $\mathrm{MP}_{2,5}$, se tornou uma das prioridades dos comitês regionais. ${ }^{52} \mathrm{~A}$ infraestrutura e logística que envolve um megaevento como o Rio 2016, pode conduzir ao aumento nas emissões atmosféricas e afetar a saúde da população e o desempenho dos atletas. Por isso, algumas medidas de controle são necessárias, tais como paralisar algumas atividades e reduzir o tráfego durante os eventos. ${ }^{89}$ Devido ao incentivo por parte do COI, alguns estudos foram realizados para avaliar a qualidade do ar antes, durante e após esse evento. A Figura 2 apresenta as concentrações médias de MP obtidas em estudos realizados em estações próximas às áreas de Jogos Olímpicos antes, durante e após o evento.

Justo et al. ${ }^{75}$ observaram as maiores concentrações de $\mathrm{MP}_{10} \mathrm{em}$ 2014 na Gávea e Botafogo, tendo sido atribuídas às obras relacionadas à Copa do Mundo de 2014 em ambos os locais. Já em 2015 as maiores concentrações foram observadas no bairro de Gericinó, sendo atribuídas às obras do Parque Olímpico de Deodoro, localizado a $300 \mathrm{~m}$ do local de amostragem. Concentrações acima do limite da OMS $\left(20 \mu \mathrm{g} \mathrm{m}^{-3}\right)$ foram registradas durante o evento, que ocorreu no período seco, o que pode ter comprometido a dispersão ou remoção de poluentes. As menores médias em 2017 podem ser atribuídas ao encerramento das obras.

No estudo realizado por Ventura et al. ${ }^{88}$ nos anos anteriores aos Jogos Olímpicos, as concentrações de $\mathrm{MP}_{10}$ foram inferiores ao limite do CONAMA e similares às encontradas em outras grandes cidades da América do Sul, com grau de desenvolvimento similar ao da cidade do Rio de Janeiro. $\mathrm{O}$ aumento de $\mathrm{MP}_{2,5}$ na região da Barra da Tijuca pode ser atribuído às obras de construção do sistema de Transporte Rápido por Ônibus (BRT). As maiores concentrações observadas em 2014 foram atribuídas às emissões geradas pela construção civil, uma vez que em 2015, após as inaugurações, as concentrações diminuíram.

Ventura et $a l .{ }^{52}$ mostraram que, apenas nas estações próximas à região olímpica de Copacabana, as concentrações de $\mathrm{MP}_{10}$ foram superiores ao limite anual do CONAMA vigente no período dos Jogos Olímpicos $\left(50 \mu \mathrm{g} \mathrm{m}^{-3}\right)$. As concentrações observadas no Rio de Janeiro foram similares às observadas em Atenas, Grécia, em 2004

Ventura et al., 2019 [88]

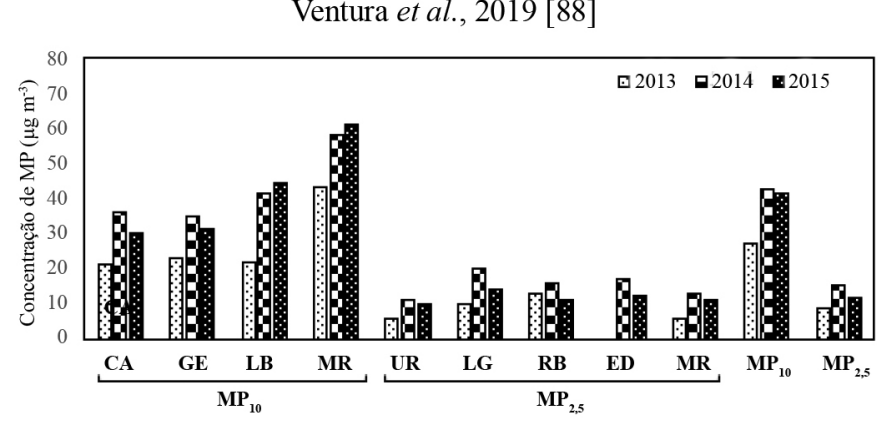

De La Cruz et al., 2018 [90]

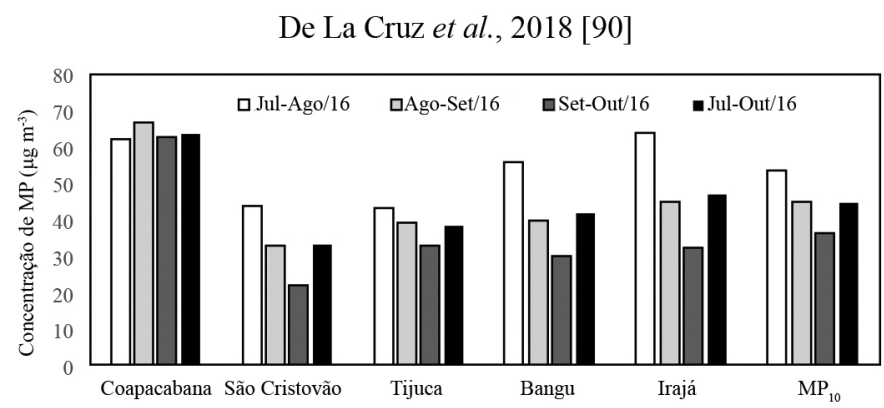

e muito inferiores às verificadas em Pequim, China, em 2008. Além disso, estas concentrações foram similares àquelas registradas no mês de agosto dos três anos anteriores. Para $\mathrm{MP}_{2,5}$ as concentrações anuais foram menores do que em anos anteriores, o que foi atribuído às modificações no tráfego da cidade, com a implantação do corredor de ônibus e do transporte rápido por ônibus.

De La Cruz et al. ${ }^{90}$ apresentaram resultados semelhantes aos de Ventura et al..$^{52}$ quanto ao $\mathrm{MP}_{10}$, pois registraram que apenas em Copacabana as concentrações foram mais altas, excedendo o limite do CONAMA.

Bezerra et al..$^{91}$ observaram que o Índice de Qualidade do Ar (IQA) apresentou valores mais baixos em 2016, o que indica ter ocorrido melhora na qualidade do ar. Os autores atribuíram tal melhora às restrições no tráfego veicular.

Tsuruta et al. ${ }^{92}$ observaram menores concentrações de $\mathrm{MP}_{10}$ durante o período olímpico, o que foi atribuído à diminuição no fluxo veicular decorrente do período de férias em escolas e universidades. A avaliação dos anos anteriores ao evento mostrou concentrações similares entre 2011 e 2015, com algumas violações do limite do CONAMA observadas entre 2013 e 2015.

\section{Resultados dos estudos da qualidade do ar realizados no estado do Rio de Janeiro}

As concentrações médias de material particulado (PTS, $\mathrm{MP}_{10}$ e $\mathrm{MP}_{2,5}$ ) estão apresentadas na Figura 3. Há grande variação nos níveis dos três tamanhos de partículas nos diferentes locais avaliados. Além disso, a amplitude dos dados em todos os locais avaliados foi acentuada, o que indica que tais locais apresentam características diferentes e variação na quantidade ou tipo de fonte de emissão.

Em 10 das 17 avaliações de PTS foram observadas médias superiores ao limite anual estabelecido pelo CONAMA $\left(80 \mu \mathrm{g} \mathrm{m}^{-3}\right)$. As maiores médias de PTS foram encontradas por Loyola et $a .^{78} \mathrm{em}$ uma estação de ônibus de Duque de Caxias e por Azevedo et al. ${ }^{82}$ em Campos do Goytacazes durante o período de queima de cana-de-açúcar.

As menores concentrações médias de PTS foram observadas por Quitério et al..$^{93}$ em Ilha Grande, uma área de preservação

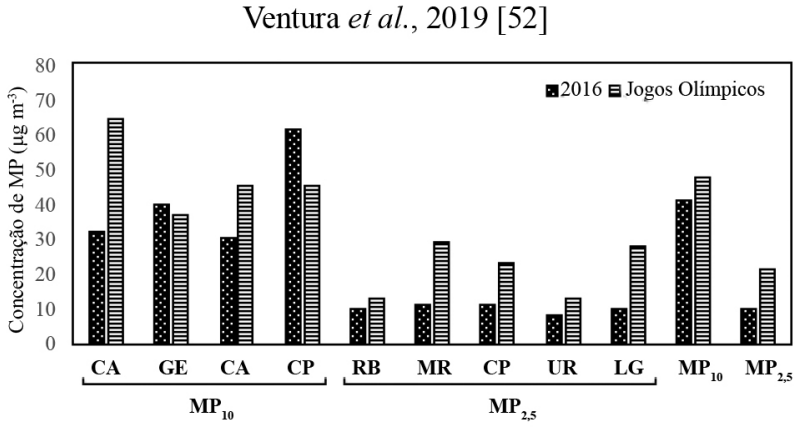

Justo et al., 2020 [75]

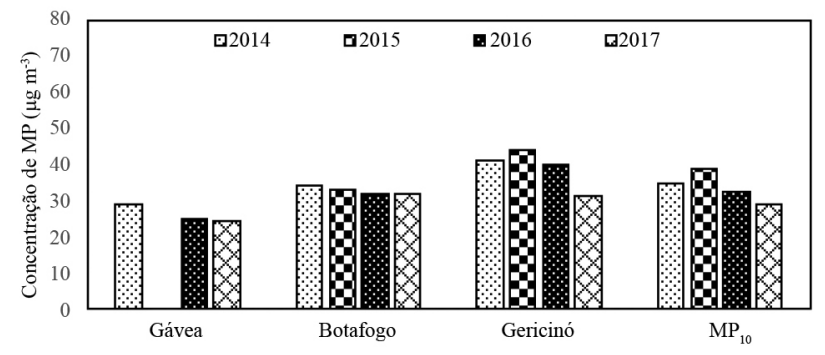

Figura 2. Concentrações médias de MP para estações próximas aos locais de Jogos Olímpicos e Paralímpicos de 2016. (CA - Campo dos Afonsos, GE - Gericinó, LB - Leblon, MR - Maracanã, UR - Urca, LG - Lagoa, RB - Recreio dos Bandeirantes, EG - Engenho de Dentro e CP - Copacabana) 

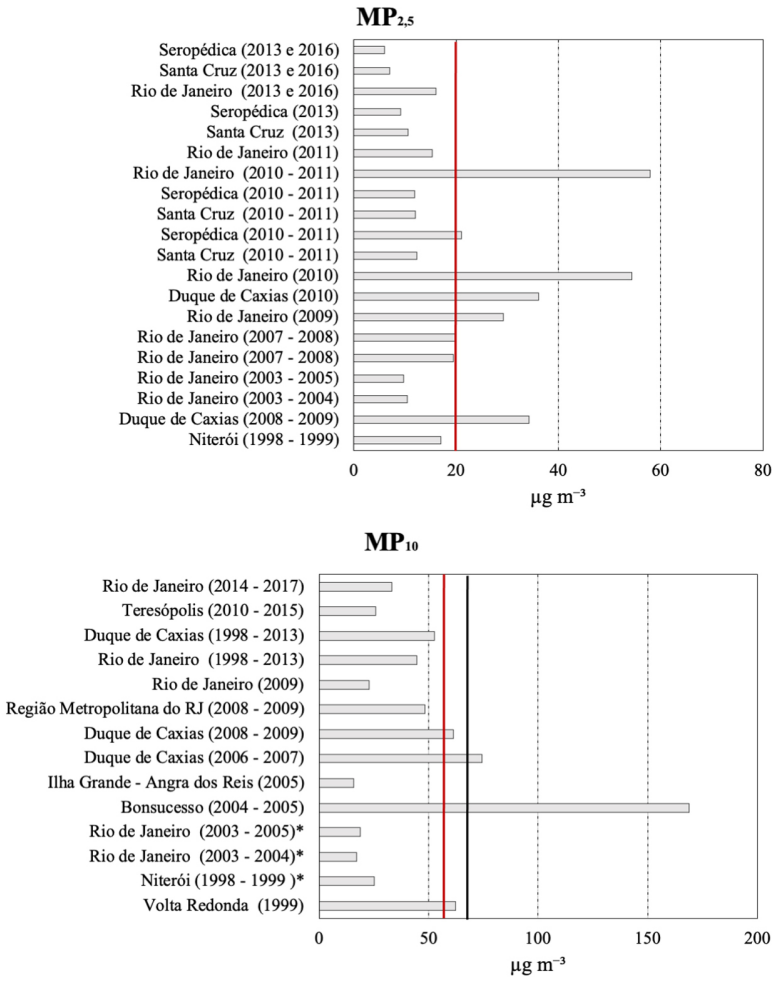

PTS

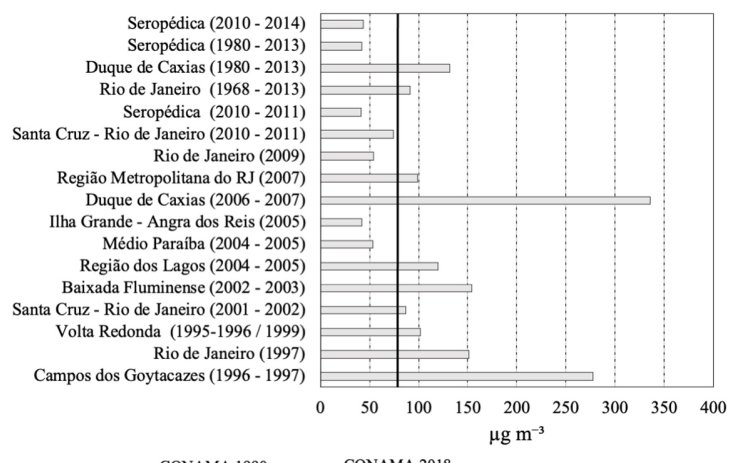

- CONAMA $1990-$ CONAMA 2018

Figura 3. Concentração média de MP encontradas nos estudos realizados no estado do Rio de Janeiro e o limite estabelecido pelo CONAMA nas resoluções de 1990 e de 2018. *Corresponde a concentração de $M P_{2,5-10}$

ambiental situada a $3 \mathrm{~km}$ do continente, onde não há tráfego de carros. Loyola et al. ${ }^{76}$ encontrou concentrações similares na região do Médio Paraíba. Embora nessa região haja atividade industrial, os autores atribuíram as baixas concentrações de PTS às medidas de controle de emissão industrial impostas pelo INEA, denominado à época de Fundação Estadual de Engenharia e do Meio Ambiente (FEEMA), pois foi observada redução na concentração de PTS de 245 para $66 \mu \mathrm{g} \mathrm{m}^{-3}$ de 1995 para 2004. Essa redução na concentração de PTS também pode ser constatada pela comparação com a média encontrada por Gioda et al. ${ }^{60}$ em Volta Redonda.

A avaliação da tendência de variação da concentração de PTS ao longo dos anos permitiu verificar que na cidade do Rio de Janeiro ocorreu diminuição entre os anos de 1997 e 2009, de tal forma que média anual passou a ser menor que o limite estabelecido pelo CONAMA. ${ }^{56,83}$

Também em Santa Cruz, bairro industrial do Rio de Janeiro, houve redução na concentração de PTS à níveis inferiores ao limite do CONAMA. ${ }^{18,61}$ Em Seropédica houve manutenção nas concentrações de PTS, mesmo considerando as médias obtidas por Gioda et al. ${ }^{11}$ para um longo período de avaliação (33 anos). Gioda et al. ${ }^{11}$ encontraram menores concentrações de PTS em Duque de Caxias do que Loyola et al. ${ }^{78}$ mas é preciso destacar que no primeiro caso o estudo se deu por um período de mais de 30 anos, o que pode contribuir para um menor valor médio do que o do segundo estudo cuja coleta foi realizada em uma estação de ônibus. Embora os estudos apresentem grandes diferenças que comprometem a comparação, em ambos foram encontradas concentrações inferiores ao limite do CONAMA.

A avaliação da concentração de $\mathrm{MP}_{10}$ incluiu 14 observações realizadas no Rio de Janeiro. Dentre elas, cinco apresentaram concentrações de $\mathrm{MP}_{10}$ maiores que o limite anual estabelecido pelo CONAMA na Resolução 003/1990, que estava vigente no período dos estudos. Entretanto, segundo os limites da nova Resolução (491/2018), as concentrações médias são maiores do que o limite anual em seis destas observações. A maior concentração de $\mathrm{MP}_{10}$ foi observada por Toledo et al. ${ }^{67} \mathrm{em}$ Bonsucesso no período entre $2004 \mathrm{e}$ 2005. Essa região, além de apresentar intenso tráfego veicular, sofre influência de indústrias do ramo petroquímico, metalúrgico, geração de energia, cerâmica e combustíveis industriais. Os autores atribuíram as elevadas concentrações de $\mathrm{MP}_{10}$ às emissões provenientes de fontes estacionárias. As menores concentrações de PTS e de $\mathrm{MP}_{10}$ foram observadas por Quitério et al. ${ }^{93}$ na Ilha Grande.

Ao comparar diferentes estudos realizados na mesma região, observa-se que em Duque de Caxias ocorreu diminuição na concentração de $\mathrm{MP}_{10}$, embora em todos eles a concentração média tenha sido maior que o limite estabelecido pelo CONAMA em 2018. A cidade do Rio de Janeiro não apresentou tendência de redução na concentração de $\mathrm{MP}_{10}$, mas os diferentes estudos revelaram variação na concentração média de $\mathrm{MP}_{10}$ para a cidade. Os estudos de Soluri et al.${ }^{65}$ e Godoy et al. ${ }^{66}$ realizados em bairros de todas as zonas da cidade, registram concentrações similares para a fração do MP com diâmetro entre 2,5 e $10 \mu \mathrm{m}$ no período entre 2003 e 2005. O estudo realizado por Loyola et al. ${ }^{56}$ no bairro do Jardim Botânico mostra concentrações ligeiramente maiores do que os reportados por Godoy et al. ${ }^{66}$ o que pode derivar da amostragem incluir também as partículas com diâmetro menor que 2,5 $\mu \mathrm{m}$. Embora o local de monitoramento deste estudo apresente fluxo intenso de carros, também está próximo a parques e áreas verdes, além de sofrer influência da brisa oceânica, por isso os autores concluíram que as fontes naturais, como a ressuspensão do solo foram as principais contribuintes para a concentração de $\mathrm{MP}_{10}$. Em um estudo mais recente, realizado por Justo et al. ${ }^{75}$ entre 2014 e 2017 nos bairros das zonas sul e oeste da cidade, concentrações de $\mathrm{MP}_{10}$ foram maiores que as encontradas por Godoy et al. ${ }^{66}$ o que pode estar associado às emissões geradas pelas obras realizadas durante a preparação da cidade para os Jogos Olímpicos de 2016.

Para $\mathrm{MP}_{2,5}$ foram consideradas 20 avaliações de amostras coletadas no estado do Rio de Janeiro. Embora durante o período no qual esses estudos foram realizados não houvesse legislação vigente que estabelecesse limite para a concentração de $\mathrm{MP}_{2,5}$, as médias anuais foram maiores que o limite estabelecido pelo CONAMA em 2018. A maior concentração foi encontrada por Rainho et al. ${ }^{84} \mathrm{em}$ um estudo realizado na cidade do Rio de Janeiro entre 2010 e 2011. Concentrações semelhantes foram observadas por Maia et al. ${ }^{58} \mathrm{em}$ Duque de Caxias em 2010. No Rio de Janeiro, as partículas foram coletadas próximo ao Túnel André Rebouças, que conecta as zonas norte e sul da cidade e nas proximidades da Avenida Brasil e Linha Vermelha, duas vias de intenso tráfego veicular, que ligam o centro da cidade à zona oeste e à Baixada Fluminense, respectivamente. Em Duque de Caxias, as partículas foram coletadas em um local situado às margens da Rodovia Federal BR-040, por onde se dá a entrada de parte das mercadorias comercializadas no estado. Além disso, o 
local de amostragem pode sofrer influência do polo petroquímico de Duque de Caxias, situado a $5 \mathrm{~km}$. A concentração de $\mathrm{MP}_{2,5}$ observada em Duque de Caxias foi cerca de 1,2 vezes maior que a encontrada por Paulino et al. ${ }^{94}$ em 2009 na mesma região e 3 vezes maior que a maioria das concentrações encontradas em estudos realizados em outras regiões do Rio de Janeiro. Além disso, foi quatro vezes maior que a concentração média encontrada em Niterói por Mariani e Mello ${ }^{64}$ no período seco durante episódios de inversão térmica em 1999. As menores concentrações de $\mathrm{MP}_{2,5}$ foram observadas por Quijano et al. ${ }^{74}$ em Santa Cruz, região industrial da cidade do Rio de Janeiro, e em Seropédica, município com características rurais.

No estado do Rio de Janeiro, principalmente na região metropolitana, a principal fonte de emissão de material particulado é a frota veicular. Essa revisão bibliográfica compreende estudos realizados durante um longo período de tempo, no qual ocorreram mudanças tanto na quantidade de veículos, quanto no fator de emissão de MP com a modernização da frota. De acordo com o Inventário Nacional de Emissões Atmosféricas por Veículos Automotores Rodoviários (2013), entre 1983 e 2012 ocorreu redução de 54 - 98\% na emissão de MP devido à queima de combustível. Esse percentual inclui veículos leves novos movidos a etanol, gasolina ou diesel, motocicletas e veículos pesados movidos a diesel..$^{95}$ Embora a modernização tenha contribuído para a redução nos fatores de emissão veicular de MP, a frota de veículos aumentou substancialmente. De acordo com o Departamento de Trânsito do estado do Rio de Janeiro (Detran), entre 2001 e 2010 o aumento da frota foi de $41 \%$ e entre 2010 e 2017 o aumento foi de $28 \%$, o que corresponde ao aumento de $58 \%$ nos 17 anos. $^{96}$

Outro fator a ser destacado é a contribuição dos municípios para a emissão dos poluentes atmosféricos. A região metropolitana do Rio de Janeiro (RMRJ) é de maior interesse devido à maior concentração populacional e, consequentemente, maior número de fontes emissoras. De acordo com o Inventário de Emissões de Fontes Veiculares realizado pelo INEA em 2013 na RMRJ, o município do Rio de Janeiro contribuía com quase $50 \%$ das emissões de MP. Dentro desse município, as zonas norte e oeste contribuíam com quase $80 \%$ das emissões veiculares.

\section{INFLUÊNCIA DAS VARIÁVEIS METEOROLÓGICAS NA CONCENTRAÇÃO DO MATERIAL PARTICULADO}

As variáveis meteorológicas (velocidade e direção dos ventos, radiação solar, temperatura, umidade relativa e precipitação pluviométrica) são importantes na avaliação da qualidade do ar, pois influenciam diretamente na dispersão de poluentes. ${ }^{97}$ Essas variáveis podem ser afetadas pelas características locais, como topografia, cobertura do solo, presença de edificações, entre outras, e consequentemente, influenciam a dispersão de poluentes..$^{98} \mathrm{~A}$ identificação da origem das massas de ar também é importante, pois auxilia na identificação das fontes de emissão que contribuem para a concentração e composição do MP de um dado local.

A maioria dos estudos realizados no Rio de Janeiro não apresenta as médias mensais de material particulado, nem separa os dados por período chuvoso ou seco, no entanto, alguns deles apresentam uma avaliação da influência da precipitação pluviométrica e da velocidade e direção dos ventos na concentração de MP.

Estudos realizados em municípios da Baixada Fluminense, município do Rio de Janeiro e no bairro Fonseca, na cidade de Niterói, mostraram que maiores concentrações de MP foram encontradas durante o período seco, que corresponde, principalmente, aos meses do inverno (junho a setembro). ${ }^{11,61-65,67,75,79,84}$ Nesses meses, a frequência da precipitação pluviométrica é menor, o que aumenta o tempo de residência das partículas na atmosfera. Foi observado que no estado do Rio de Janeiro as temperaturas mais baixas favoreceram a inversão térmica, que contribui para a estagnação dos poluentes na atmosfera, dificultando sua dispersão. ${ }^{52,64,66}$

O estudo realizado por Mariani e Mello ${ }^{64}$ em Niterói reporta resultados referentes aos períodos seco e úmido, demonstrando que durante o período seco foram encontradas concentrações de $\mathrm{MP}_{10} \mathrm{e}$ $\mathrm{MP}_{2,5}$ até 1,8 vezes maiores que as encontradas durante o período úmido. Embora as concentrações tenham sido maiores no período seco, a razão entre os dois tamanhos de partículas não foi afetada. A manutenção desta razão pode indicar que as fontes de emissão permaneceram as mesmas nos dois períodos e que a diminuição das concentrações de MP no período úmido pode ser atribuída ao maior volume de precipitação pluviométrica neste período.

Ainda que o estudo realizado em Niterói tenha demonstrado manutenção na razão entre as partículas, as condições meteorológicas observadas em diferentes estações do ano podem favorecer a formação de um tamanho de partícula em detrimento do outro, alterando assim a razão entre diferentes frações do MP. A formação de partículas por nucleação é favorecida no período úmido, devido às suas características higroscópicas, que podem incluir o processo de nucleação homogênea. A formação de partículas pelo modo de Aitken dá-se, preferencialmente, no período seco, pois o processo de formação envolve reações heterogêneas. A variação na razão entre os tamanhos de partículas pode ser melhor observada quando é feita a separação da fração fina do MP, pois partículas formadas por nucleação e pelo modo de Aitken possuem tamanhos que variam de 2,5 a $100 \mathrm{~nm}$. Mariani e Mello ${ }^{64}$ relatam que as partículas formadas por esses processos estão incluídas no $\mathrm{MP}_{2,5}$ o que justifica a manutenção da razão em comparação com a fração grossa nos períodos seco e úmido. ${ }^{99}$

Mateus et al. ${ }^{85}$ reportam concentrações para PTS e $\mathrm{MP}_{10}$ referentes aos períodos secos e úmidos de 2010 a 2015 em Seropédica e Teresópolis. As concentrações de PTS em Seropédica não apresentaram variação sazonal, embora em 2011 tenham sido observadas concentração 1,5 vezes maiores no período seco e em 2014 concentrações 1,6 vezes maiores no período úmido. Para $\mathrm{MP}_{10}$ foram encontradas concentrações 1,7 - 3 vezes maiores no período seco em 2010 e 2011, enquanto que entre 2012 e 2015 foram observadas concentrações similares para períodos secos e úmidos.

A velocidade e a direção dos ventos podem contribuir para a dispersão ou estagnação dos poluentes. Alguns dos estudos realizados no Rio de Janeiro consideraram a influência dessas variáveis meteorológicas na concentração de MP, uma vez que podem contribuir para a atribuição das fontes..$^{59-61,63,67}$ No estudo desenvolvido por Sella et al. ${ }^{63} \mathrm{em}$ Cabo Frio, foi observada uma anomalia nas concentrações de MP no mês de março, atribuída aos ventos de origem continental com baixa velocidade ocorridos durante esse mês. Nos demais meses, os ventos predominantes foram de origem marinha. Paulino et al..$^{59}$ observaram que em Duque de Caxias o vento de origem marinha contribuiu para o transporte dos poluentes emitidos nessa região industrial para o continente, além de promover mistura dos poluentes na atmosfera. Isto resultou em pequenas diferenças nas concentrações entre os locais de amostragem. Justo et al. ${ }^{75}$ relatam que, em alguns bairros do Rio de Janeiro, os ventos fracos, a baixa umidade do ar e a pouca precipitação durante os meses de inverno contribuem para ocorrência de concentrações de $\mathrm{MP}_{10}$ mais elevadas.

Em geral, as avaliações da influência das variáveis meteorológicas na concentração do MP mostram que nos períodos chuvosos são encontradas concentrações menores. $\mathrm{O}$ aumento da precipitação pluviométrica e da umidade relativa do ar auxiliam na remoção de poluentes da atmosfera via deposição úmida. A sazonalidade exerceu um efeito similar nos locais de monitoramento, uma vez que cada estação do ano apresenta um perfil de precipitação. Assim, menores 
concentrações de MP foram observadas nas estações do ano mais chuvosas.

\section{CARACTERIZAÇÃO QUÍMICA DO MP}

A USEPA estabelece métodos de referência para a caracterização química do MP. De acordo com o método $\mathrm{IO}$ - 3.1, a determinação da composição elementar do MP pode ser realizada por XRF, diretamente nos filtros contendo as partículas, ou através de extração utilizando solução ácida ou micro-ondas para quantificação por ICP-MS, já a quantificação de íons pode ser realizada por cromatografia de íons (CI) após extração aquosa. ${ }^{100}$

O preparo das amostras é realizado utilizando-se uma alíquota dos filtros contendo material particulado. Para os filtros usados no Hi-Vol, a alíquota sugerida pela USEPA é de 2,54 $\mathrm{cm}$ x 20,32 $\mathrm{cm}$ para obter a área de $51,6 \mathrm{~cm}^{2}$, que contempla toda a extensão do filtro. Entretanto, nos estudos realizados no Rio de Janeiro, a área do filtro utilizada para extração variou de $9-129 \mathrm{~cm}^{2} .{ }^{18,54,56-58,60-63,67,74-76,78,85,93,94,100,101}$ Para os filtros utilizados no SFU, cada alíquota pode ser formada por frações que correspondem de 25 a $75 \%$ dos filtros ${ }^{65,66}$ De acordo com Marrero et. al., ${ }^{102}$ não existe uma região preferencial no filtro para a deposição dos metais, além disso, a maioria dos elementos apresenta homogeneidade satisfatória, com diferenças menores de $15 \%$ entre as regiões do filtro. Após o corte da alíquota do filtro ela dever ser transferida para um tubo plástico para determinação gravimétrica de sua massa.

\section{Caracterização iônica}

A extração das espécies solúveis em água é feita através da adição de água ultrapura com condutividade ajustada no purificador $\left(0,055 \mu \mathrm{S} \mathrm{cm}^{-1}\right)$. Dois procedimentos podem ser adotados para essa extração: sonicação em ultrassom ${ }^{7,18,64-66,103,104}$ ou agitação em vortex por 1-2 min..$^{47,74,75,85}$ Posteriormente, o extrato é centrifugado e o sobrenadante filtrado com membrana de porosidade de $0,22-0,45 \mu \mathrm{m}$ para remoção de partículas insolúveis. O extrato obtido após a filtração deve ser analisado de imediato ou congelado até que seja feita a quantificação por cromatografia de íons. Embora no Método 300.1 da USEPA ${ }^{105}$ a recomendação seja o uso de membranas com porosidade de $0,45 \mu \mathrm{m}$ para determinação de íons, o filtro com porosidade $0,22 \mu \mathrm{m}$ também é usado, pois garante a remoção de partículas ainda menores, além de também remover o material microbiológico.

\section{Caracterização elementar}

Nos estudos realizados no Rio de Janeiro, a caracterização elementar das partículas se deu segundo algumas adaptações das recomendações da USEPA para a extração ácida. No entanto, a quantificação também foi realizada por ICP OES e FAAS, além de ICP-MS, técnica sugerida pela agência ambiental. ${ }^{18,60,103}$

A recomendação da USEPA é que seja utilizada uma alíquota do filtro para cada tipo de extração. No entanto, alguns estudos utilizaram a mesma alíquota para a extração aquosa (caracterização iônica) seguida da extração ácida (caracterização elementar). ${ }^{7}$ Após a adição do ácido, a amostra é aquecida a $100^{\circ} \mathrm{C}$ entre $2 \mathrm{~h} \mathrm{a} 4 \mathrm{~h}$ e, posteriormente, resfriada e diluída com água ultrapura.

De acordo com o método IO - 3.1 ${ }^{100}$ da USEPA, a mistura $\mathrm{HCl} / \mathrm{HNO}_{3}$ é recomendada para a extração dos elementos metálicos, tendo sido usada em muitos estudos. . $^{5,56,58,59,61,62,67}$

Entretanto, a caracterização elementar do material particulado também tem sido realizada utilizando metodologias alternativas para a extração ou lixiviação dos elementos. Esses procedimentos incluem a extração por micro-ondas ou utilização de outras soluções ácidas como as mistura $\mathrm{HNO}_{3}-\mathrm{HF}$ ou adição de reagentes oxidantes como $\mathrm{HClO}_{4}$ ou $\mathrm{H}_{2} \mathrm{O}_{2}$. Salcedo et al. ${ }^{106}$ compararam tais métodos e verificaram que a utilização da mistura $\mathrm{HNO}_{3}-\mathrm{HF}$ apresentou resultados satisfatórios para a maioria dos elementos. No entanto, a utilização dos oxidantes não aumentou a eficiência de extração.

É importante destacar que para a utilização de HF algumas medidas de prevenção são necessárias. Esse ácido provoca dor e necrose dos tecidos imediatamente ao entrar em contato com eles, pois os íons fluoreto penetram as membranas lipídicas rapidamente. ${ }^{107}$ Devido ao seu poder de corrosão e à toxidade, o HF deve ser usado por profissionais capacitados e em locais apropriados. Alguns equipamentos de proteção necessários são: escudos faciais, luvas e óculos de borracha, aventais resistentes ao ácido e filtro respiratório. ${ }^{108}$ Além disso a compra desse reagente é controlada pelo Exército Brasileiro e pela Polícia Civil, pois é considerado agente precursor de guerra química.

Mateus et al. ${ }^{18}$ relatam que, em comparação ao método USEPA, a utilização apenas de $\mathrm{HNO}_{3}$ leva à maior eficiência de extração (EE) a partir do material de referência certificado NIST-SRM 1648a - Urban dust. Os valores elevados indicam que o método que utiliza apenas $\mathrm{HNO}_{3}$ é adequado para lixiviação de metais presentes nas partículas. Foi observada baixa recuperação para alguns metais refratários que, no entanto, estão em forma não biodisponível. Portanto, o procedimento não compromete os resultados dos estudos, uma vez que o foco é o impacto na saúde ou no ecossistema. Devido à melhora na $\mathrm{EE}$, alguns autores optaram pela extração que utiliza apenas $\mathrm{HNO}_{3}{ }^{7,47,74,81,103,109}$

\section{Controle de qualidade}

Para obter dados confiáveis da composição química do MP são realizadas, por técnicas espectrométricas e por cromatografia de íons, respectivamente, análise dos ácidos e da água ultrapura utilizados na extração elementar e solubilização. Para verificar a eficiência da extração ácida usam-se materiais certificados de referência (MCR) (ex., SRM 1648a, urban dust e SRM 2783, air particulate matter, NIST, EUA), aplicando-se os mesmos procedimentos de extração utilizados para os filtros contendo MP. A fim de assegurar a homogeneidade do filtro contendo o MP, algumas amostras são extraídas em replicatas. A precisão e a exatidão dos equipamentos de análise são garantidas pelo uso sistemático de um padrão de check e de duplicata de algumas amostras.

Alguns analitos de interesse estão presentes na composição dos filtros brancos, por isso é necessário determinar suas concentrações para que sejam descontadas da concentração final. Para avaliar a composição dos filtros brancos, matriz da amostra, o mesmo procedimento para extração ácida e aquosa deve ser aplicado a algumas alíquotas destes filtros (tiras nas dimensões 1,7 x $21 \mathrm{~cm}$ ). As concentrações dos analitos de interesse encontrados nos filtros brancos devem ser descontadas na concentração final das amostras. Assim, para que as concentrações dos analitos no material particulado não sejam subestimadas ou superestimadas, os valores obtidos para os filtros brancos podem ser submetidos ao teste de Grubbs visando a remoção de outliers antes de serem descontados das concentrações obtidas para as amostras. ${ }^{13,47}$

Os limites de detecção (LD) e quantificação (LQ) instrumentais para as análises elementares são obtidos através do desvio padrão de 10 medições do ácido (usado na extração, de acordo com as equações 1 e 2 .

$$
\begin{gathered}
L D_{I C P-M S}=3 \times s_{H N O 3} \\
L Q_{I C P-M S}=10 \times s_{H N O 3}
\end{gathered}
$$


Os limites de detecção e quantificação instrumentais para a cromatografia de íons são calculados considerando o padrão de menor concentração usado para a confecção da curva analítica, de acordo com a equação 3 proposta por Soluri, ${ }^{110}$ em que $S_{y 1}$ é o desvio padrão das concentrações obtidas nas análises da solução padrão de menor concentração, $x_{1}$ é a concentração teórica para a solução padrão de menor concentração e $y_{m}$ é a média das concentrações obtidas nas análises da solução padrão de menor concentração. O LQ pode ser calculado a partir do LD de acordo com a equação $4 .{ }^{110}$

$$
\begin{gathered}
L D_{C I}=\frac{3,3\left(S_{y 1} \times x_{1}\right)}{y_{m}} \\
L Q_{C I}=3 \times L D_{C I}
\end{gathered}
$$

Devido à presença de analitos de interesse na composição do filtro de fibra de vidro, matriz das amostras, devem ser calculados LD e LQ para o método. Os limites do método são obtidos considerando a média de concentração de cada íon ou elemento nos filtros brancos $\left(x_{\text {analito }}\right)$ e o desvio padrão das concentrações de elementos e íons encontradas nos filtros brancos $\left(s_{\text {analito }}\right)$, de acordo com a equações 5 e 6 .

$$
\begin{gathered}
L D_{\text {método }}=x_{\text {analito }}+\left(3 \times s_{\text {analito }}\right) \\
L D_{\text {método }}=3 \times L D_{\text {método }}
\end{gathered}
$$

\section{INTERPRETAÇÃO DOS DADOS DE COMPOSIÇÃO QUÍMICA DO MP}

\section{Fator de Enriquecimento}

O fator de enriquecimento (FE) é um valor utilizado para prever a contribuição das fontes antropogênicas para a composição elementar do MP. Seu cálculo consiste na normalização dos valores pela concentração de um elemento abundante no solo, como Al e Fe, de acordo com a equação 7, proposta por Olmez et al., ${ }^{11}$ em que $C_{x}$ é a concentração do analito de interesse e $C_{r e f}$ é a concentração de um elemento de referência encontrada no solo. $\mathrm{O}$ valor do FE é dado pela razão entre as proporções do analito e elemento de referência na amostra e no solo. ${ }^{11,112}$

$$
F E=\frac{\left(\frac{C_{x}}{C_{r e f}}\right)_{\text {amostra }}}{\left(\frac{C_{x}}{C_{r e f}}\right)_{\text {solo }}}
$$

Para os elementos presentes no MP, valores de $\mathrm{FE}=1$ indicam fonte exclusivamente do solo, dessa forma, quanto mais próximo da unidade, maior a contribuição natural para a composição. Valores de $\mathrm{FE}>5$ representam enriquecimento causado por fontes antropogênicas. ${ }^{113}$ Considera-se que $5<\mathrm{FE}<10$ indicam contribuição de fontes próximas ao local de coleta das partículas. ${ }^{114}$

\section{Contribuição marinha para composição do MP}

A cidade do Rio de Janeiro e alguns municípios vizinhos estão submetidos à influência das massas de ar de origem oceânica. Elas podem carregar aerossóis emitidos pelos oceanos, também denominados spray marinho, que é uma importante fonte de íons. $\mathrm{Na}$ água do mar os íons são encontrados em razões constantes e bem definidas, o que permite avaliar a contribuição marinha para a concentração de espécies iônicas no MP.

Uma abordagem utilizada para avaliar a contribuição das espécies de origem não marinha (non sea salt - nss) é fazer a consideração de que toda a concentração de $\mathrm{Na}^{+}$encontrada nas amostras é proveniente do mar (sea salt - ss). Por meio das proporções conhecidas entre o cátion de sódio (ou magnésio) e os outros íons é possível calcular a concentração dos íons que seria de origem marinha, que se descontada da concentração total obtida para cada íon fornecerá a concentração de $n s s$. Com base nas razões das concentrações dos íons presentes na água do mar e a concentração de $\mathrm{Na}^{+}$, Morales et al. ${ }^{4}$ propôs equações (8-12) para o cálculo do nss, que foram aplicadas em estudos realizados no Rio de Janeiro. ${ }^{57,65,66}$

$$
\begin{gathered}
n s s-\mathrm{Ca}^{2+}=C_{\mathrm{Ca}^{2+}}-0,038 \times C_{\mathrm{Na}^{+}} \\
n s s-\mathrm{Mg}^{2+}=C_{\mathrm{Mg}^{2+}}-0,12 \times C_{\mathrm{Na}^{+}} \\
n s s-\mathrm{K}^{+}=C_{\mathrm{K}^{+}}-0,035 \times C_{\mathrm{Na}^{+}} \\
n s s-\mathrm{SO}_{4}^{2-}=C_{\mathrm{SO}_{4}^{2-}}-0,25 \times C_{\mathrm{Na}^{+}} \\
n s s-\mathrm{Cl}^{-}=C_{\mathrm{Cl}^{-}}-1,727 \times C_{\mathrm{Na}^{+}}
\end{gathered}
$$

\section{Acidez do material particulado}

Os componentes do material particulado determinam sua acidez ou basicidade. A acidez do MP pode afetar suas propriedades químicas, porque pode induzir às reações entre substâncias do estado gasoso e os componentes das partículas. Além disso, partículas com acidez elevada contribuem para a formação da chuva ácida, uma vez que atuam como núcleos de condensação para a precipitação pluviométrica. ${ }^{115}$ Devido aos processos de formação, a fração fina tende a apresentar acidez mais elevada, pois apresenta maior contribuição de ânions de ácidos fortes. Por outro lado, a fração mais grossa apresenta maior capacidade de neutralização devido a presença de cátions de bases fortes em partículas emitidas por fontes naturais ou construção civil. ${ }^{46,116-118}$

Os íons presentes no MP podem ter características ácidas ou básicas, sendo assim, dependendo de suas concentrações, é possível ocorrer neutralização da acidez ou basicidade das partículas. O grau de neutralização pode então ser usado como um indicador da acidez do MP. A neutralização é calculada por meio da razão entre o somatório das concentrações molares dos cátions (com características básicas) e dos ânions (com características ácidas), considerando a carga de cada íon. Valores menores que 1 indicam que a neutralização não foi completa, de tal forma que as partículas podem ser consideradas ácidas. ${ }^{15}$

\section{COMPOSIÇÃO ELEMENTAR DO MATERIAL PARTICULADO}

\section{Concentração média dos elementos no MP}

O tamanho das partículas pode influenciar na concentração de seus constituintes devido aos processos de formação ou à diferença nas massas das partículas. As Tabelas 2 a 5 apresentam as faixas de concentração dos elementos metálicos e espécies iônicas encontradas no MP coletado no Rio de Janeiro entre 1995 e 2017.

Os principais elementos encontrados nas partículas, considerando os três tamanhos avaliados, foram Fe e Al. As maiores concentrações para esses elementos foram observadas por Quitério et al. ${ }^{61} \mathrm{em}$ em Santa Cruz, bairro do Rio de Janeiro que abriga um complexo siderúrgico. As emissões das indústrias próximas aos locais de amostragem podem ter contribuído para concentrações muito elevados desses elementos nas PTS, assim como a ressuspensão da poeira do solo provocada pelo tráfego de caminhões utilizados pelas companhias industriais. Em outros estudos realizados em áreas não industriais, tais elementos também apareceram como principais componentes do MP, juntamente com $\mathrm{Zn}$. Esses elementos fazem 
parte da composição do solo, o que explica suas altas concentrações nas PTS, uma vez que partículas provenientes da ressuspensão do solo tendem a possuir diâmetros maiores. ${ }^{3,15}$ Alguns estudos revelam a importância do Zn na composição do MP do Rio de Janeiro pois, além de estar presente na composição do solo este elemento também pode estar associado às emissões veiculares, queima de combustível fóssil e emissões geradas por atividades industriais. ${ }^{57,104}$

Dentre os elementos minoritários destacam-se $\mathrm{Cr}, \mathrm{Cu}, \mathrm{Pb}$ e $\mathrm{Cd}$. As maiores concentrações de $\mathrm{Cr}$ e $\mathrm{Pb}$ foram observadas por Quitério et $a l .{ }^{61}$ nas PTS coletadas em Santa Cruz e as de Cd por Quitério et al. ${ }^{62} \mathrm{em}$ Nova Iguaçu. Os autores atribuíram a fonte desses elementos às atividades industriais existentes nas regiões de amostragem, como siderurgia e metalurgia. Para corroborar a origem antropogênica de tais elementos, foi calculado o fator de enriquecimento com relação à composição do solo, encontrandose valores de até 1200 , o que indica que esses elementos são majoritariamente de origem antropogênica.

A maior concentração de $\mathrm{Cu}$ foi observada por Gioda et $a .^{7}{ }^{\mathrm{em}}$ $\mathrm{MP}_{10}$ coletado em Duque de Caxias, entretanto, valores similares foram observados também no centro do Rio de Janeiro, local que apresentou maior média anual para esse elemento dentre os locais de monitoramento desse estudo. Os autores atribuem a origem de $\mathrm{Cu}$ no centro do Rio de Janeiro à queima de óleo e combustível e às emissões provenientes do tráfego veicular, já que apresentou boas correlações com $\mathrm{Pb}$ e $\mathrm{Cd}$, mas em Duque de Caxias a emissão de $\mathrm{Cu}$ também pode ser atribuída aos processos metalúrgicos.

Alguns elementos metálicos podem ser associados aos danos à saúde humana, sendo classificados como substâncias carcinogênicas. Embora a regulação da concentração dessas espécies químicas no ar não seja muito comum, a exceção do $\mathrm{Pb}$, a comissão europeia e alguns outros países estabelecem limites para a concentração dos elementos $\mathrm{Cr}, \mathrm{Ni}, \mathrm{Cd}$ e As.

De acordo com a Resolução do CONAMA 491/2018, o limite da média anual de concentração de $\mathrm{Pb}$ medido em PTS deve ser de 0,5 $\mu \mathrm{g} \mathrm{m}{ }^{-3}$. Gioda et al. ${ }^{60} \mathrm{e}$ Quitério et al.${ }^{61}$ encontraram concentrações até 6 vezes superiores ao limite em estudos realizados em Volta Redonda (1995 - 1999) e Santa Cruz (2001 - 2002), respectivamente. É importante ressaltar que, de acordo com a legislação, o monitoramento de $\mathrm{Pb}$ é indicado para regiões com potencial de emissão. Como esses dois locais apresentam importantes complexos siderúrgicos, os valores encontrados indicam que esses empreendimentos industriais contribuíam para emissões que colocava a população da região em risco. Um estudo realizado posteriormente na região de Volta Redonda (2004 - 2005) por Loyola et al. ${ }^{76}$ registrou concentrações de $\mathrm{Pb}$ até 35 vezes menores que o limite atual de $\mathrm{Pb}$ em PTS. Mateus et al. ${ }^{18}$ encontraram em Santa Cruz (2010 - 2011) concentrações de Pb até 50 vezes menores do que o padrão de qualidade do ar. A redução na concentração de $\mathrm{Pb}$ nessas regiões industriais indica que a modernização das indústrias contribuiu para o controle das emissões.

A comissão europeia estabelece valores limites para a concentração de $\mathrm{Ni}\left(20 \mathrm{ng} \mathrm{m}^{-3}\right)$ e $\mathrm{Cd}\left(5 \mathrm{ng} \mathrm{m}^{-3}\right)$. O estudo desenvolvido por Gioda et al. ${ }^{60}$ em Volta Redonda revela concentrações de Ni e $\mathrm{Cd}$ de 1,5-2,8 vezes superiores às recomendações europeias tanto em PTS quanto em $\mathrm{MP}_{10}$. Para Cd, também foram encontradas, por Quitério et al. ${ }^{62}$ concentrações quase 100 vezes maiores em Nova Iguaçu.

\section{Fator de enriquecimento do MP coletado no Rio de Janeiro}

Para avaliar a influência das contribuições naturais e antropogênicas na composição do MP, alguns estudos fizeram uso do fator de enriquecimento. Paulino et al. ${ }^{59}$ verificaram que o MP emitido no município de Duque de Caxias apresentou percentuais de Fe, Zn, Ca e
$\mathrm{Cu}$ mais elevados que os verificados para a crosta terrestre, indicando que atividades antropogênicas contribuíram para a presença de tais elementos nas partículas, principalmente o tráfego de carros e as indústrias petroquímicas presentes nessa região. Maia et al..$^{58}$ também verificaram enriquecimento desses elementos na mesma região e observaram, ainda, enriquecimento de Ni. Além da contribuição das atividades industriais e queima de combustíveis por veículos, alguns desses elementos podem ser emitidos por desgastes de peças dos carros, como os pneus e as lonas de freio. ${ }^{58,119}$

Quitério et al. ${ }^{62}$ encontraram $\mathrm{FE}$ altos para $\mathrm{Zn}, \mathrm{Cu}, \mathrm{Cd}$ e $\mathrm{Pb}$ no estudo realizado próximo às siderúrgicas de Santa Cruz, indicando maior contribuição de fontes antropogênicas para esses elementos. Foram encontrados ainda valores moderados para $\mathrm{Mn}$ e $\mathrm{Ni}$, o que indica que as fontes naturais e antropogênicas apresentam contribuições similares.

No estudo realizado por Loyola et al. ${ }^{56}$ no túnel André Rebouças, situado entre as zonas sul e norte da cidade do Rio de Janeiro, foi verificado enriquecimento muito elevado para $\mathrm{Zn}$ e $\mathrm{Cu}$, cerca de 10 vezes maior que o observado em outros estudos. Sabe-se que a dispersão de poluentes em túneis é dificultada devido a contínua emissão, principalmente em túneis longos como o Túnel Rebouças que possui $2,8 \mathrm{~km}$ de comprimento. ${ }^{120}$ Os veículos são responsáveis pela emissão desses elementos, uma vez que podem estar presentes na gasolina ou no diesel. Além disso, o Zn faz parte da composição dos pneus, podendo ser emitido em seu desgaste, e o Cu está presente nas lonas de freio, também emitido pelo desgaste. ${ }^{34,119}$ No estudo realizado por Loyola et al. ${ }^{78}$ em uma estação de ônibus em Duque de Caxias, também foram observados enriquecimentos elevados de $\mathrm{Cu}$ e $\mathrm{Zn}$, confirmando a associação desses elementos às emissões provenientes do tráfego veicular.

Ao avaliar-se a composição do MP emitido em diferentes regiões do estado do Rio de Janeiro, observa-se que os maiores FE são encontrados para $\mathrm{Zn}, \mathrm{Cu}, \mathrm{Cd}$ e $\mathrm{Pb}$, o que mostra que tais elementos estão associados às emissões antropogênicas, principalmente as veiculares e das atividades industriais. Em algumas regiões observa-se ainda enriquecimento de outros elementos que também podem ser associados às atividades antropogênicas, como Ni, Fe e Mn.

\section{COMPOSIÇÃO IÔNICA DO MATERIAL PARTICULADO}

\section{Concentração média dos íons no MP}

As espécies iônicas podem representar até $70 \%$ do material particulado, por isso, suas concentrações, comumente, são superiores às concentrações dos elementos metálicos. Dentre os 30 estudos sobre MP realizados no Rio de Janeiro, apenas 11 avaliaram a composição iônica das partículas. As faixas de concentração média para os íons nas partículas estão apresentadas nas Tabela 2 a 5.7,57,64-66,75,79,121

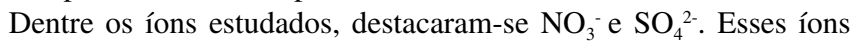
estão associados à queima de combustíveis fósseis, por isso, são encontrados em concentrações elevadas em centros urbanos, onde a principal fonte de emissão são os veículos.

Apenas Mateus et al..$^{18}$ avaliaram a composição iônica das PTS, determinando as concentrações de $\mathrm{Cl}^{-}, \mathrm{NO}_{3}{ }^{-}$e $\mathrm{SO}_{4}{ }^{2-}$ em partículas coletadas em Santa Cruz e Seropédica. Esses íons foram encontrados em faixas de concentração similares, estando relacionados às características de formação das partículas. $\mathrm{O} \mathrm{Cl}^{-}$pode ser emitido diretamente para a atmosfera, como um poluente primário, portanto, tende a estar presente em partículas maiores, já $\mathrm{NO}_{3}{ }^{-}{\mathrm{e} \mathrm{SO}_{4}{ }^{2-} \text { são }}$ formados por reações que ocorrem na atmosfera, portanto a sua maior associação às partículas de tamanhos menores. Outro fator que pode ainda ser considerado para entender as menores concentrações de $\mathrm{Cl}^{-}$em partículas finas é a depleção de $\mathrm{Cl}^{-}$por meio de reações no 


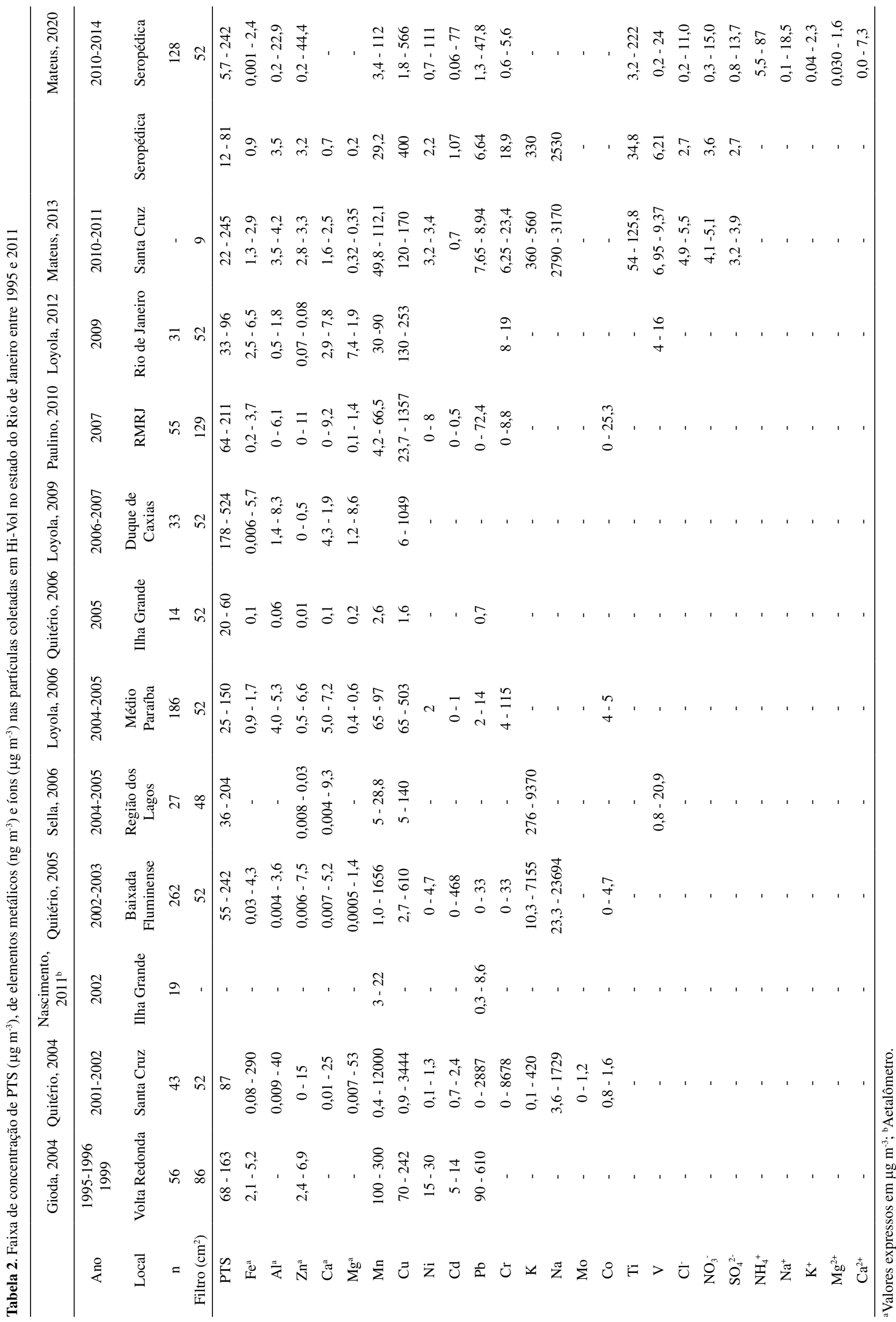




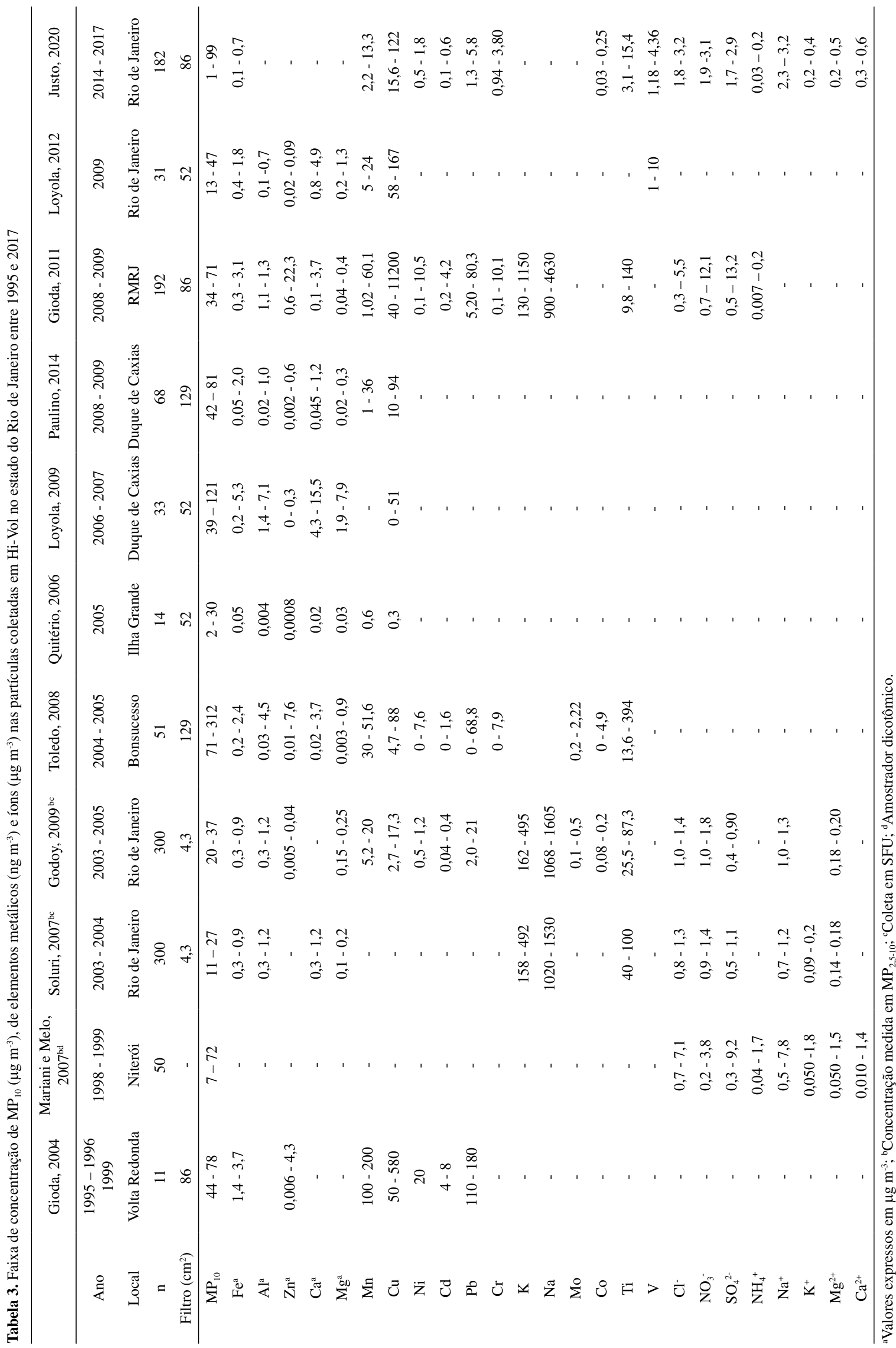


Tabela 4. Faixa de concentração de $\mathrm{MP}_{2,5}\left(\mu \mathrm{g} \mathrm{m}^{-3}\right)$, elementos metálicos $\left(\mathrm{ng} \mathrm{m}^{-3}\right)$ e íons $\left(\mu \mathrm{g} \mathrm{m}^{-3}\right)$ nas partículas coletadas em Hi-Vol no estado do Rio de Janeiro entre 1998 e 2009

\begin{tabular}{|c|c|c|c|c|c|c|c|}
\hline & $\begin{array}{l}\text { Mariani e Melo, } \\
2007^{c}\end{array}$ & Soluri, $2007^{\mathrm{b}}$ & Godoy, 2009 b & Paulino, 2014 & Miranda, 2012 & Andrade, $2012^{\mathrm{d}}$ & Loyola 2012 \\
\hline Ano & $1998-1999$ & $2003-2004$ & $2003-2005$ & $2008-2009$ & $2007-2008$ & $2007-2008$ & 2009 \\
\hline Local & Niterói & Rio de Janeiro & Rio de Janeiro & Duque de Caxias & Rio de Janeiro & Rio de Janeiro & Rio de Janeiro \\
\hline $\mathrm{n}$ & 50 & 300 & 300 & 110 & 150 & 150 & 50 \\
\hline Filtro $\left(\mathrm{cm}^{2}\right)$ & - & 4,3 & 4,3 & 129 & 2,7 & - & 52 \\
\hline $\mathrm{MP}_{2,5}$ & $3-63$ & $7-13$ & $7-11$ & $21-45$ & $2-62$ & - & $8-117$ \\
\hline $\mathrm{Fe}^{\mathrm{a}}$ & - & $0,07-0,1$ & $0,09-1,5$ & $0,008-1,2$ & 0,07 & 0,08 & $0,183-0,570$ \\
\hline $\mathrm{Al}^{\mathrm{a}}$ & - & $0,07-0,2$ & $0,06-0,2$ & $0,02-0,4$ & 0,05 & 0,05 & 0 \\
\hline $\mathrm{Zn}^{\mathrm{a}}$ & - & - & $0,007-0,02$ & $0,008-0,4$ & 0,02 & 0,03 & $0,006-0,042$ \\
\hline $\mathrm{Ca}^{\mathrm{a}}$ & - & $0,05-0,1$ & - & $0,004-0,6$ & 0,04 & 0,004 & $0,028-0,143$ \\
\hline $\mathrm{Mg}^{\mathrm{a}}$ & - & $0,02-0,03$ & $0,02-0,03$ & $0,006-0,2$ & - & 0,008 & $0,009-0,051$ \\
\hline $\mathrm{Mn}$ & - & - & $2,4-6,3$ & $1-18$ & 4,4 & 41 & $0-11$ \\
\hline $\mathrm{Cu}$ & - & - & $4,2-12,9$ & $4-97$ & 8,8 & - & $16-135$ \\
\hline $\mathrm{Ni}$ & - & - & $0,9-1,6$ & - & 2,2 & 3 & - \\
\hline $\mathrm{Cd}$ & - & - & $0,1-2,1$ & - & & - & - \\
\hline $\mathrm{Pb}$ & - & - & $1,6-2,1$ & - & 11,8 & 12 & - \\
\hline $\mathrm{Cr}$ & - & - & - & - & 1,8 & 2 & 0 \\
\hline $\mathrm{K}$ & - & $91-169$ & $97,8-194$ & - & 183 & 178 & - \\
\hline $\mathrm{Na}$ & - & $160-280$ & $214-286$ & - & - & - & - \\
\hline Mo & - & - & $0,08-0,3$ & - & - & - & - \\
\hline $\mathrm{Co}$ & - & - & $0,03-0,07$ & - & - & - & - \\
\hline $\mathrm{Ti}$ & - & $17-25$ & $9,4-15,5$ & - & 5,5 & 6 & - \\
\hline $\mathrm{V}$ & - & - & - & - & 4,5 & 4 & $0-4$ \\
\hline $\mathrm{Cl}^{-}$ & $0,050-1,2$ & $0,1-0,3$ & $0,1-1,4$ & - & 0,1 & 0,1 & - \\
\hline $\mathrm{NO}_{3}^{-}$ & $0,03-2,3$ & $0,3-0,5$ & $0,2-1,6$ & - & 0,6 & 0,6 & - \\
\hline $\mathrm{SO}_{4}^{2-}$ & $0,3-5,0$ & $1,4-2,2$ & $0,5-1,4$ & - & 1,9 & 1,9 & - \\
\hline $\mathrm{NH}_{4}^{+}$ & $0,06-2,8$ & $0,4-0,7$ & - & - & 0,8 & 0,8 & - \\
\hline $\mathrm{Na}^{+}$ & $0,1-0,8$ & $0,2-0,3$ & $0,2-0,4$ & - & 0,2 & 0,2 & - \\
\hline $\mathrm{K}^{+}$ & $0,05-2,3$ & $0,1-0,2$ & - & - & & - & - \\
\hline $\mathrm{Mg}^{2+}$ & $0,03-0,1$ & - & $0,05-0,071$ & - & & - & - \\
\hline $\mathrm{Ca}^{2+}$ & $0,01-0,03$ & - & - & - & - & - & - \\
\hline
\end{tabular}

${ }^{\mathrm{a}}$ Valores expressos em $\mu \mathrm{g} \mathrm{m}{ }^{-3}$; ${ }^{\mathrm{b}}$ Coleta em SFU; ${ }^{\mathrm{c}}$ Amostrador dicotômico; ${ }^{\mathrm{d}}$ Harvard impactor.

estado gasoso. Os íons $\mathrm{NO}_{3}{ }^{-} \mathrm{e} \mathrm{SO}_{4}{ }^{2-}$ formam os ácidos $\mathrm{HNO}_{3}$ e $\mathrm{H}_{2} \mathrm{SO}_{4}$, quando em contato com $\mathrm{H}_{2} \mathrm{O}$, que reagem com $\mathrm{Cl}^{-}$produzindo $\mathrm{NO}_{3}{ }^{-} \mathrm{e}$ $\mathrm{HCl}$ gasoso, removendo assim os íons cloreto da fase particulada. ${ }^{122}$

Nos estudos relacionados à fração $\mathrm{MP}_{10}$, as maiores concentrações de $\mathrm{NO}_{3}{ }^{-} \mathrm{e} \mathrm{SO}_{4}{ }^{2-}$ foram encontradas por Gioda et al. ${ }^{7}$ em Duque de Caxias, um município do Rio de Janeiro que, além de muito populoso, apresenta rodovias de fluxo intenso, incluindo o transporte de carga, e um importante complexo industrial onde está localizado um polo petroquímico. Nesse tamanho de partícula destacaram-se também as concentrações de $\mathrm{Cl}^{-}$relatadas por Mariani e $\mathrm{Melo}^{64}$ em Niterói e por Gioda et al. ${ }^{7}$ e Justo et al. ${ }^{75}$ em estudos realizados no Rio de Janeiro. Nessas duas cidades há grande influência das massas de ar de origem oceânica e, por isso, espera-se a presença de $\mathrm{Cl}^{-}$no $\mathrm{MP}$, principalmente nas frações mais grossas.

Para $\mathrm{MP}_{2,5}$ as maiores concentrações de $\mathrm{NO}_{3}{ }^{-}$foram observadas por Quijano et. al. ${ }^{74}$ em Copacabana, um bairro residencial-comercial da cidade do Rio de Janeiro, onde a principal fonte de poluentes são os veículos. A razão $\mathrm{NO}_{3}{ }^{-} / \mathrm{SO}_{4}{ }^{2-}$ maior que 1 indica que ocorreu maior contribuição das fontes móveis, caracterizadas por concentração de nitrato predominante em relação ao sulfato. As maiores concentrações de $\mathrm{SO}_{4}{ }^{2-}$ foram observadas por Mariani e $\mathrm{Melo}^{64}$ no estudo realizado em Niterói.

\section{Avaliação da contribuição marinha na composição do MP}

As concentrações médias dos íons apresentadas nos estudos de avaliação da composição iônica foram usadas para calcular a contribuição não marinha para a composição do MP.

A maioria dos estudos sobre a fração do MP solúvel em água apresentou percentuais elevados de $n s s$ para $\mathrm{Ca}^{2+}, \mathrm{K}^{+} \mathrm{e} \mathrm{SO}_{4}{ }^{2-}$, indicando que a maior fonte desses íons não é marinha. Os menores percentuais de $n s s$ foram encontrados para $\mathrm{Mg}^{2+}$, o que indica ser este íon majoritariamente proveniente do spray marinho.

Soluri et al ${ }^{65}$ realizaram estudo em locais com fortes influências de atividades antropogênicas e verificaram que, para a fração fina do material particulado, houve contribuição de nss maior que $90 \%$ para a concentração de $\mathrm{K}^{+}$e $\mathrm{SO}_{4}{ }^{2-}$, enquanto para a fração grossa os percentuais diminuíram para a faixa de $50 \%$ a $70 \%$ de nss. A maior contribuição não marinha para a fração fina pode estar associada à formação do MP por processos de combustão, que tendem a gerar partículas com diâmetros menores, enquanto aquelas presentes no spray marinho tendem a se associar à fração mais grossa. Comportamento semelhante foi encontrado posteriormente por Godoy et al. ${ }^{66} \mathrm{em}$ estudo realizado nos mesmos locais de amostragem.

Em um estudo realizado em Niterói por Mariani e Mello, ${ }^{64}$ 
Tabela 5. Faixa de concentração de $\mathrm{MP}_{2,5}\left(\mu \mathrm{g} \mathrm{m}^{-3}\right)$, elementos metálicos $\left(\mathrm{ng} \mathrm{m}^{-3}\right)$ e íons $\left(\mu \mathrm{g} \mathrm{m}^{-3}\right)$ em $\mathrm{MP}_{2,5}$ coletadas em Hi-Vol no estado do Rio de Janeiro entre 2010 e 2016

\begin{tabular}{|c|c|c|c|c|c|c|c|c|c|c|c|}
\hline & Maia, 2014 & Mateus & 2013 & Mateu & 2017 & $\begin{array}{c}\text { Ventura, } \\
2017\end{array}$ & Mateu & 2017 & & uijano, 201 & \\
\hline Ano & 2010 & $2010-$ & 2011 & 2010 & 2011 & 2011 & & 13 & & 2013 e 2016 & \\
\hline Local & $\begin{array}{c}\text { Duque de } \\
\text { Caxias }\end{array}$ & Santa Cruz & Seropédica & Santa Cruz & Seropédica & $\begin{array}{l}\text { Rio de } \\
\text { Janeiro }\end{array}$ & Santa Cruz & Seropédica & $\begin{array}{l}\text { Rio de } \\
\text { Janeiro }\end{array}$ & Santa Cruz & Seropédica \\
\hline $\mathrm{n}$ & 17 & 18 & & & . & 206 & & & & - & \\
\hline Filtro $\left(\mathrm{cm}^{2}\right)$ & 129 & 9 & & & ) & - & & & & 62 & \\
\hline $\mathrm{MP}_{2,5}$ & $12-74$ & - & - & $1-43$ & $1-35$ & $1-67$ & $2-37$ & $3-26$ & $7-19$ & 7 & 6 \\
\hline $\mathrm{Fe}^{\mathrm{a}}$ & $0,002-0,2$ & $0,12-0,15$ & 0,14 & - & - & $0,1-0,7$ & - & - & - & 1,0 & 0,7 \\
\hline $\mathrm{Al}^{\mathrm{a}}$ & & $5,5-5,6$ & 5,4 & - & - & $1,6-6,7$ & - & - & - & 2,1 & 1,2 \\
\hline $\mathrm{Zn}^{\mathrm{a}}$ & $0,07-0,6$ & $5,4-5,6$ & 5,1 & - & - & $1,9-6,6$ & - & - & - & 2,9 & 1,8 \\
\hline $\mathrm{Ca}^{\mathrm{a}}$ & $0,02-0,1$ & $0,2-0,3$ & 0,2 & - & - & $1,2-7,6$ & - & - & - & - & - \\
\hline $\mathrm{Mg}^{\mathrm{a}}$ & $0,006-0,03$ & 0,050 & 0,07 & - & - & $0,1-1,2$ & - & - & - & 0,6 & 0,4 \\
\hline $\mathrm{Mn}$ & & $5,9-7,3$ & 7,2 & 20,5 & & $4,1-17$ & - & - & 1,6 & 10,7 & 14,6 \\
\hline $\mathrm{Cu}$ & $1,1-121,3$ & $10-60$ & 50 & 37,7 & 51 & $17-71$ & 15,6 & 18,4 & $6,7-47$ & 19,7 & 123 \\
\hline $\mathrm{Ni}$ & $0-7,7$ & $1,8-2,1$ & 1,7 & 1,6 & 1,8 & $1,7-5,2$ & 1,1 & 0,90 & $0,8-3$ & 1,5 & 2,3 \\
\hline $\mathrm{Cd}$ & $0-2,2$ & $0,68-0,72$ & 1,1 & - & - & $0,4-1,5$ & - & - & $0,2-0,5$ & 2,2 & 2,8 \\
\hline $\mathrm{Pb}$ & $0-9,9$ & $6,2-7,9$ & 6,2 & - & - & $5,2-36$ & - & - & $0,3-7,6$ & 12,5 & 13,8 \\
\hline $\mathrm{Cr}$ & $0-1,7$ & $4,6-5,0$ & 2,2 & - & - & $1,2-2,7$ & - & - & - & 4,1 & 6,8 \\
\hline $\mathrm{K}$ & - & $0,2-0,3$ & 230 & - & - & $1000-5100$ & - & - & - & 1,2 & 0,8 \\
\hline $\mathrm{Na}$ & - & $1,3-1,6$ & 1590 & - & - & $5800-13000$ & - & - & - & 4,4 & 6,4 \\
\hline Mo & - & - & - & - & - & - & - & - & $0,09-0,1$ & 0,3 & 0,4 \\
\hline $\mathrm{Co}$ & - & - & - & - & - & - & - & - & - & - & - \\
\hline $\mathrm{Ti}$ & - & $7,9-8,1$ & 7,69 & 8,2 & 7,7 & $7300-66000$ & 7,3 & 6,9 & - & 9,6 & 15,4 \\
\hline $\mathrm{V}$ & - & $3,9-4,4$ & 3,03 & 5,1 & 4,8 & - & & & $1,0-8,1$ & 2,5 & 3,0 \\
\hline $\mathrm{Cl}^{-}$ & - & $0,9-1,0$ & 1,1 & 1,0 & 1,2 & - & 0,5 & 0,4 & & & \\
\hline $\mathrm{NO}_{3}^{-}$ & - & $1,3-1,6$ & 1,7 & 1,5 & 1,7 & - & 1,0 & 0,8 & $0,55-5,0$ & 0,8 & 0,7 \\
\hline $\mathrm{SO}_{4}^{2-}$ & - & $2,9-3,8$ & 3,3 & 3,7 & 3,7 & - & 2,7 & 2,7 & $1,7-3,9$ & 2,8 & 2,7 \\
\hline $\mathrm{NH}_{4}^{+}$ & - & - & - & - & - & - & - & - & $0,01-0,02$ & - & - \\
\hline $\mathrm{Na}^{+}$ & - & - & - & - & - & - & - & - & $1,9-2,2$ & 1,4 & 1,4 \\
\hline $\mathrm{K}^{+}$ & - & - & - & 0,09 & 0,1 & - & 0,2 & 0,2 & $0,06-0,2$ & - & - \\
\hline $\mathrm{Mg}^{2+}$ & - & - & - & 0,3 & 0,2 & - & 0,070 & 0,060 & $0,03-0,04$ & 0,03 & - \\
\hline $\mathrm{Ca}^{2+}$ & - & - & - & 0,2 & 0,2 & - & 0,3 & 0,23 & $0,2-0,4$ & 0,11 & 0,06 \\
\hline
\end{tabular}

Valores expressos em $\mu \mathrm{g} \mathrm{\textrm {m } ^ { - 3 }}$.

também foi observada contribuição elevada de $n s s$ para $\mathrm{K}^{+} \mathrm{e} \mathrm{SO}_{4}^{2-}$, principalmente na fração fina. A contribuição não marinha para $\mathrm{Ca}^{2+}$ foi semelhante nos dois tamanhos de partículas e para o $\mathrm{Mg}^{2+}$ foi maior para a fração mais grossa, portanto mostrou variação oposta ao reportado por Soluri et al.${ }^{65} \mathrm{e}$ Godoy et al. ${ }^{66}$ De acordo com os autores, a contribuição não marinha para $\mathrm{Ca}^{2+}$ pode resultar da construção civil, das emissões provenientes da vegetação e da queima de biomassa no período seco. Essa última fonte de emissão também foi associada à contribuição não marinha de $\mathrm{K}^{+} \mathrm{e} \mathrm{Mg}^{2+}$.

Gioda et al. $^{7}$ observaram em 2008 e 2009 elevada contribuição de $n s s$ para os íons $\mathrm{K}^{+}, \mathrm{Ca}^{2+}$ e $\mathrm{SO}_{4}^{2-}$ nos quatro locais estudados. Os valores foram similares, mesmo comparando locais com características urbana, industrial ou rural. A maior diferença foi encontrada para $\mathrm{Mg}^{2+}$ que apresentou maior contribuição não marinha no local rural, o que pode ser atribuído à maior distância do mar e à queima de biomassa que ocorre na região.

Quijano et al. ${ }^{74}$ observaram que a contribuição não marinha

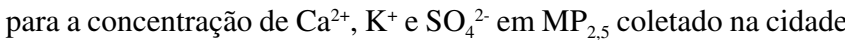
do Rio de Janeiro encontrou-se entre 51 e $88 \%$. Dentre esses íons, $\mathrm{SO}_{4}^{2-}$ foi o que apresentou as maiores contribuições não marinhas, com percentuais similares entre os locais urbanos e rural. Para os outros íons não foi possível fazer essa comparação, pois não foram detectados nas amostras coletadas no local rural. Resultados similares foram obtidos por Justo et al. ${ }^{75} \mathrm{em} \mathrm{MP}{ }_{10}$, que observaram contribuições não marinhas para $\mathrm{Ca}^{2+}, \mathrm{K}^{+} \mathrm{e} \mathrm{SO}_{4}{ }^{2-}$ entre $58 \%$ e $80 \%$. Assim como no estudo de Quijano et al. ${ }^{74}$ foi observada depleção em $\mathrm{Mg}^{2+}$.

Miranda et al. ${ }^{79}$ e Andrade et al. ${ }^{121}$ determinaram alguns íons no $\mathrm{MP}_{2,5}$ coletado na cidade do Rio de Janeiro. Em ambos os estudos foram observadas contribuições de origem não marinha de $97 \%$ para a concentração de $\mathrm{SO}_{4}{ }^{2-}$. No estudo mais recente, desenvolvido por Mateus et al. ${ }^{85}$ em regiões de florestas localizadas nos municípios de Seropédica e Teresópolis, a maior contribuição para $\mathrm{K}^{+}, \mathrm{Ca}^{2+} \mathrm{e}$ $\mathrm{SO}_{4}{ }^{2-}$ em PTS e $\mathrm{MP}_{2,5}$ foi de origem não marinha, assim como nos outros estudos realizados no estado.

\section{Avaliação da acidez do material particulado}

Godoy et al. ${ }^{66}$ reportam resultados que indicam que as partículas finas apresentam caráter mais ácido do que as grossas, no entanto, não foram determinados íons alcalinos que poderiam ser importantes para a neutralização dos ânions. Esse fato é salientado pela deficiência 
de cátions observada por meio do balanço de íons, uma medida da razão entre cátions e ânions. A menor acidez das partículas grossas pode decorrer de menores concentrações de $\mathrm{SO}_{4}{ }^{2-}$ evidenciada pelo aumento na razão $\mathrm{NO}_{3}{ }^{-} / \mathrm{SO}_{4}{ }^{2-}$. No estudo de Soluri et al. ${ }^{65}$ a tendência observada foi oposta, embora o cátion $\mathrm{NH}_{4}{ }^{+}$tenha sido determinado apenas nas partículas finas. Isto pode ter contribuído para o grau de neutralização mais elevado nas partículas $\mathrm{MP}_{2,5}$.

No estudo de Mariani e Mello, ${ }^{64} \mathrm{o}$ grau de neutralização indicou leve basicidade das partículas, possivelmente em decorrência das concentrações mais baixas de $\mathrm{NO}_{3}{ }^{-}$. Os baixos teores de nitrato podem ter resultado da volatilização deste íon encontrado na forma de $\mathrm{NH}_{4} \mathrm{NO}_{3}$, uma vez que os filtros de Teflon ${ }^{\circledR}$, utilizados nesse estudo, facilitam a volatilização dessa substância. ${ }^{123} \mathrm{~A}$ deficiência de íons de caráter ácido é confirmada pelo balanço de íons.

Os estudos realizados por Gioda et al. ${ }^{7}$ e Justo et al. ${ }^{75}$ mostraram que o $\mathrm{MP}_{10}$ apresentou maior grau de neutralização, evidenciado pelo balanço de íons próximos da unidade.

Miranda et al..$^{79}$ relataram, também, que amostras de $\mathrm{MP}_{2,5}$ apresentaram boa capacidade de neutralização. No entanto, nesse estudo não foi feita a determinação de alguns cátions que poderiam contribuir para a alcalinidade das partículas. Quijano et al. ${ }^{74}$ observaram que o $\mathrm{MP}_{2,5}$ coletado em locais urbanos apresentou leve acidez, enquanto que nos locais rural e industrial o grau de neutralização foi maior. Esse fato pode ser atribuído à maior concentração de nitrato nos locais urbanos, enquanto baixos valores da razão $\mathrm{NO}_{3}{ }^{-} / \mathrm{SO}_{4}{ }^{2-}$ ocorrem nos locais rural e industrial.

Mateus et al. ${ }^{85}$ mostraram a ocorrência de padrões diferentes da acidez do MP. As PTS e o $\mathrm{MP}_{2,5}$ mostraram graus de neutralização elevados, o que indica basicidade das partículas. Esse resultado pode ser relacionado ao deficit de ânions em relação aos cátions e também às baixas razões $\mathrm{NO}_{3}-/ \mathrm{SO}_{4}{ }^{2-}$.

\section{CONCLUSÕES}

Os estudos sobre concentração e composição do MP realizados no Brasil apresentam como um dos objetivos gerar informações que indiquem para o governo a necessidade de atualizações nas legislações ambientais. Após quase três décadas, a legislação brasileira relacionada à qualidade do ar foi atualizada visando atender as recomendações da OMS. No entanto, alterações dos padrões de qualidade do ar não garantem que os poluentes serão reduzidos, porque é necessário que ocorra monitoramento atmosférico para verificar se as concentrações encontradas no ar se adequam à legislação. $\mathrm{O}$ monitoramento de poluentes atmosféricos no Brasil é ineficiente, pois apenas 9 das 27 unidades da federação apresentam rede de monitoramento.

O estado do Rio de Janeiro foi um dos pioneiros na instalação de redes de monitoramento da qualidade do ar, por isso apresenta dados de concentração de MP desde a década de 1960. Embora os amostradores de MP apresentem larga distribuição, o que torna possível a obtenção de informações sobre a qualidade do ar em diferentes regiões do estado, a maioria dos estudos são conduzidos na região metropolitana.

As maiores concentrações de MP (PTS, $\mathrm{MP}_{10}$ e $\mathrm{MP}_{2,5}$ ) foram observadas em locais com forte influência de atividades antropogênicas, como tráfego veicular e indústrias, enquanto menores concentrações estão em locais mais afastados dos grandes centros urbanos, onde poucas fontes antropogênicas são encontradas. Ao longo dos anos observou-se redução da concentração de MP, principalmente em Santa Cruz e Volta Redonda, o que pode ser associado à modernização dos complexos industriais instalados nesses dois locais. Na cidade do Rio de Janeiro e de Duque de Caxias há variações nas concentrações dos três tamanhos de partícula dentro do período avaliado e concentrações acima dos limites do CONAMA.
Os principais elementos que fazem parte da composição do material particulado são Fe e Al, seguidos do Zn. Esses elementos são comumente associados à composição do solo, mas também podem ser emitidos por algumas fontes antropogênicas. A contribuição mista para a concentração desses elementos foi verificada pelo FE. Outros elementos como $\mathrm{Ni}, \mathrm{Pb}, \mathrm{Cu}, \mathrm{Cd}$ e $\mathrm{Mn}$ foram encontrados em concentrações traço e seus altos FE indicaram que são de origem antropogênica. Assim como observado para as concentrações de MP, Santa Cruz e Volta Redonda também apresentaram reduções na concentração de alguns elementos ao longo dos anos.

A fração do MP solúvel em água é composta majoritariamente pelos ânions $\mathrm{NO}_{3}{ }^{-}$e $\mathrm{SO}_{4}{ }^{2-}$, que são traçadores de emissões veiculares. A avaliação da contribuição marinha para a composição iônica do MP mostrou que em grande parte dos estudos $\mathrm{Ca}^{2+}, \mathrm{K}^{+} \mathrm{e} \mathrm{SO}_{4}{ }^{2-}$ apresentaram maior contribuição de outras fontes, enquanto $\mathrm{Mg}^{2+}$ é majoritariamente proveniente do mar. A estimativa do grau de neutralização no MP mostrou que, na maioria dos estudos nos quais as espécies solúveis foram quantificadas, as partículas possuíam caráter ácido, o que pode ser atribuído às altas concentrações dos íons de ácidos forte $\mathrm{NO}_{3}{ }^{-} \mathrm{e}$ $\mathrm{SO}_{4}{ }^{2}$. Isso indica a possibilidade de ocorrência de chuva ácida nos locais monitorados, o que representa um risco para a população, ecossistemas, monumentos e o meio ambiente como um todo.

As variáveis meteorológicas exercem grande influência na concentração e composição do MP, portanto, nos períodos de maiores volumes de precipitações pluviométricas as concentrações foram menores em períodos menos chuvosos foram mais elevadas. A sazonalidade afetou de maneira similar os diferentes pontos de amostragens, uma vez que as condições meteorológicas do estado apresentam semelhanças, sendo observados período chuvosos durante primavera e verão e períodos secos durante outono e inverno.

A avaliação da qualidade do ar do estado do Rio de Janeiro vem se mostrando eficiente, principalmente devido ao interesse de pesquisadores, no entanto, faz-se necessário a ampliação da área de estudo, pois poucos trabalhos são desenvolvidos no interior do estado, onde outras fontes de poluentes precisam ser avaliadas. $\mathrm{O} 1^{\circ}$ Diagnóstico da Rede de Monitoramento da Qualidade do Ar do Brasil demonstrou que embora seja pioneiro nesse monitoramento, o estado ainda precisa investir mais, visto que foi observada descontinuidade no funcionamento de muitas estações e a invalidação de uma quantidade significativa de dados. Além disso, estudos futuros deveriam considerar outras substâncias que podem fazer parte da composição do MP, uma vez que novos poluentes são lançados na atmosfera com o passar dos anos devido à modernização de equipamentos e processos de produção. Visando melhorar a qualidade do ar, estabelecer projetos de cooperação entre instituições de pesquisa e agências ambientais governamentais ainda é um desafio a ser vencido.

\section{MATERIAL SUPLEMENTAR}

Algumas tabelas com dados considerados neste trabalho estão disponíveis em http://quimicanova.sbq.org.br, na forma de arquivo PDF, com acesso livre.

\section{AGRADECIMENTOS}

Este estudo foi parcialmente financiado pela Coordenação de Aperfeiçoamento de Pessoal de Nível Superior - Brasil (CAPES) - Código Financeiro 001, CNPq, FAPERJ, PIBIC, INEA. À Prof ${ }^{\mathrm{a}}$. Angela Wagener (PUC-Rio) pela correção gramatical do artigo.

\section{REFERÊNCIAS}

1. Seinfeld, J. H.; Pandis, S. N.; Noone, K.; Phys. Today 1998, 51, 1326. 
2. Lenzi, E.; Fávero, L. O. B.; Introdução à Química da Atmosfera: Ciência, Vida e Sobrevivência; $1^{\text {a }}$ ed.; Rio de Janeiro, 2008.

3. Alves, C. A.; Quim. Nova 2005, 28, 859.

4. Morales, J. A.; Pirela, D.; De Nava, M. G.; De Borrego, B. S.; Velásquez, H.; Durán, J.; Atmos. Res. 1998, 46, 307.

5. Kim, K.; Kabir, E.; Kabir, S.; Environ. Int. 2015, 74, 136.

6. Sanderson, P.; Delgado-Saborit, J. M.; Harrison, R. M.; Atmos. Environ. 2014, 94, 353.

7. Gioda, A.; Amaral, B. S.; Monteiro, I. L. G.; Saint'Pierre, T. D.; J. Environ. Monit. 2011, 13, 2134.

8. Spencer, J.; Van Heyst, B.; Canadian Biosystems Engineering / Le Genie des Biosystems Au Canada 2019, 60, 69.

9. He, M. Z.; Zeng, X.; Zhang, K.; Kinney, P. L.; Int. J. Environ. Res. Public Health 2017, 14.

10. Fuzzi, S.; Baltensperger, U.; Carslaw, K.; Decesari, S.; Gon, H. D. Van Der; Facchini, M. C.; Fowler, D.; Nazionale, C.; Atmos. Chem. Phys. 2015, 15, 8217.

11. Gioda, A.; Maria, L.; Ventura, B.; Ramos, M. B.; Palagano, M.; Silva, R.; Water Air Soil Pollut. 2016, 227:86, 1.

12. Pöschl, U.; Atmos. Chem. 2005, 44, 7520 .

13. Ventura, L. M. B.; de Oliveira Pinto, F.; Soares, L. M.; Luna, A. S.; Gioda, A.; Meteorol. Atmos. Phys. 2018, 130, 361.

14. Al-Thani, H.; Koç, M.; Isaifan, R. J.; Environ. Sci. Pollut. Res. 2018, 25 , 27839.

15. Seinfeld, J. H.; Pandis, S. N. In Atmospheric Chemistry and Physics: From air pollution to climate change; Sons, J. W., ed.; $2^{\text {nd }}$ ed.; Wiley: Hoboken, 2006.

16. Grantz, D. A.; Garner, J. H. B.; Johnson, D. W.; Environ. Int. 2003, 29, 213.

17. Gulia, S.; Shiva Nagendra, S. M.; Khare, M.; Khanna, I.; Atmos. Pollut. Res. 2015, 6, 286.

18. Mateus, V. L.; Monteiro, I. L. G.; Rocha, R. C. C.; Saint'Pierre, T. D.; Gioda, A.; Spectrochim. Acta, Part B 2013, 86, 131.

19. Santos, L. B. dos; Almeida, A. C.; Godoy, J. M.; Quim. Nova 2017, 15, 1.

20. Bell, M.; Davis, D. L.; Fletcher, T.; Environ. Health Perspect. 2004, 112, 6.

21. Ware, J. H.; Thibodeau, L. A.; Speizer, E.; Environ. Health Perspect. 1981, Vol. 41, 255

22. Calef, D.; Goble, R.; Policy Sci. 2007, 40, 1.

23. Giles, L. V.; Brauer, M.; Barn, P.; Künzli, N.; Romieu, I.; Mittleman, M. A.; van Eeden, S.; Allen, R.; Carlsten, C.; Stieb, D.; Noonan, C.; Smargiassi, A.; Kaufman, J. D.; Hajat, S.; Kosatsky, T.; Brauer, M.; Environ. Health Perspect. 2011, 119, 29.

24. Landrigan, P. J.; Lancet Public Heal. 2017, 2, e4.

25. WHO Air Polution, available at https://www.who.int/health-topics/airpollution\#tab=tab_1, accessed at February 2021.

26. Atkinson, R. W.; Fuller, G. W.; Anderson, H. R.; Harrison, R. M.; Atkinson, R. W.; Fuller, G. W.; Anderson, H. R.; Harrison, R. M.; Armstrong, B.; Lippincott Williams \& Wilkins 2010, 21, 501.

27. Löndahl, J.; Pagels, J.; Swietlicki, E.; Zhou, J.; Ketzel, M.; Massling, A.; Bohgard, M.; J. Aerosol Sci. 2006, 37, 1152.

28. Fajersztajn, L.; Saldiva, P.; Pereira, L. A. A.; Leite, V. F.; Buehler, A. M.; Int. J. Public Health 2017, 62, 729.

29. Saldiva, P. H. N.; Arden Pope, C.; Schwartz, J.; Dockery, D. W.; Lichtenfels, A. J.; Marcos Salce, J.; Barone, I.; Miklos Bohm, C.; Arch. Environ. Health 1995, 50, 159.

30. Kisku, G. C.; Pradhan, S.; Khan, A. H.; Bhargava, S. K.; Air Quality, Atmosphere, and Health 2013, 6, 509.

31. Hamra, G. B.; Guha, N.; Cohen, A.; Laden, F.; Raaschou-Nielsen, O.; Samet, J. M.; Vineis, P.; Forastiere, F.; Saldiva, P.; Yorifuji, T.; Loomis, D.; Environ. Health Perspect. 2014, 122, 906

32. Pereira, L. A. A.; Loomis, D.; Conceijo, G. M. S.; Braga, A. L. F.;
Arcas, R. M.; Kishi, H. S.; Singer, J. M.; Bohm, G. M.; Saldiva, P. H. N.; Environ. Health Perspect. 1998, 106, 325.

33. Hays, M. D.; Cho, S. H.; Baldauf, R.; Schauer, J. J.; Shafer, M.; Atmos. Environ. 2011, 45, 925

34. Lin, C. C.; Chen, S. J.; Huang, K. L.; Hwang, W. I.; Chang-Chien, G. P.; Lin, W. Y.; Environ. Sci. Technol. 2005, 39, 8113.

35. Song, F.; Gao, Y.; Atmos. Environ. 2011, 45, 6714.

36. Cepeda, M.; Schoufour, J.; Freak-Poli, R.; Koolhaas, C. M.; Dhana, K.; Bramer, W. M.; Franco, O. H.; Lancet Public Health 2017, 2, e23.

37. Pope, C. A.; Thun, M. J.; Namboodiri, M. M.; Dockery, D. W.; Evans, J. S.; Speizer, F. E.; Heath, C. W.; Am. J. Respir. Crit. Care Med. 1989, $151,669$.

38. Guaita, R.; Pichiule, M.; Maté, T.; Linares, C.; Díaz, J.; Guaita, R.; Pichiule, M.; Maté, T.; Linares, C.; Int. J. Environ. Health Res. 2011, 21, 260.

39. Mölter, A.; Agius, R. M.; Vocht, F. De; Lindley, S.; Gerrard, W.; Lowe, L.; Environ. Health Perspect. 2013, 121, 1232.

40. Datta, S.; Rahman, S.; Borhan, M. S.; Saini-Eidukat, B.; Cihacek, L.; Ringwall, K. In ASABE Meeting Presentation; Orlando, EUA, 2016.

41. Rai, P. K.; Ecotoxicol. Environ. Saf. 2016, 129, 120.

42. Chen, L.; Liu, C.; Zou, R.; Yang, M.; Zhang, Z.; Environ. Pollut. 2016, 208, 198.

43. Escobedo, F. J.; Kroeger, T.; Wagner, J. E.; Environ. Pollut. 2011, 159, 2078.

44. Baldauf, R.; Transp. Res. Part D 2017, 52, 354

45. González, C. M.; Aristizábal, B. H.; Atmos. Environ. 2012, 60, 164.

46. Wu, W.; Zhang, Y.; Environ. Sci. Pollut. Res. 2018, 25, 30720.

47. Mateus, V. L.; Gioda, A.; Atmos. Environ. 2017, 164, 147.

48. Shen, Z.; Cao, J.; Arimoto, R.; Han, Z.; Zhang, R.; Han, Y.; Liu, S.; Okuda, T.; Nakao, S.; Tanaka, S.; Atmos. Environ. 2009, 43, 2911.

49. Bilos, C.; Colombo, J. C.; Skorupka, C. N.; Rodriguez Presa, M. J.; Environ. Pollut. 2001, 111, 149.

50. Sousa, E. T.; Lopes, W. A.; De Andrade, J. B.; Quim. Nova 2016, 39, 486

51. IEMA Primeiro diagnóstico da rede de monitoramento da qualidade do ar no Brasil; 2014.

52. Ventura, L. M. B.; Ramos, M. B.; Gioda, A.; França, B. B.; de Oliveira Godoy, J. M.; Environ. Monit. Assess. 2019, 191, 369.

53. Instituto Estadual do Ambiente Monitoramento do Ar, Emissões e Qualidade, disponível em http://www.inea.rj.gov.br/Portal/ MegaDropDown/Monitoramento/Monitoramentodoar-EmiQualidade/ index.htm\&lang=, acessado em fevereiro 2021.

54. Paulino, S. D. A.; Quiterio, S. L.; Escaleira, V.; Arbilla, G.; Bull. Environ. Contam. Toxicol. 2010, 84, 315.

55. Nascimento, F. S. Do; Losno, R.; Colin, J. L.; De Mello, W. Z.; Da Silva, H. E.; Water. Air. Soil Pollut. 2011, 214, 525.

56. Loyola, J.; Arbilla, G.; Quiterio, S. L.; Escaleira, V.; Minho, A. S.; J. Braz. Chem. Soc. 2012, 23, 628.

57. Mateus, V. L.; Gioda, A.; Atmos. Environ. 2017, 164, 147.

58. Maia, M.; Quitério, S. L.; Lopes, R.; Loyola, J.; Arbilla, G.; Perspectivas da Ciência e Tecnologia (IFRJ) 2014, 6, 2.

59. Paulino, S. D. A.; Oliveira, R. L.; Loyola, J.; Minho, A. S.; Arbilla, G.; Quiterio, S. L.; Escaleira, V.; Bull. Environ. Contam. Toxicol. 2014, 92, 590.

60. Gioda, A.; Sales, J. A.; Cavalcanti, P. M. S.; Maia, M. F.; Maia, L. F. P. G.; Aquino Neto, F. R.; J. Braz. Chem. Soc. 2004, 15, 856.

61. Quiterio, S. L.; Sousa da Silva, C. R.; Arbilla, G.; Escaleira, V.; Atmos. Environ. 2004, 38, 321.

62. Quiterio, S. L.; Sousa, C. R.; Arbilla, G.; Escaleira, V.; Atmos. Environ. 2005, 39, 3503

63. Sella, S. M.; Neves, A. F.; Moreira, J. C.; Silva-Filho, E. V.; Atmos. Environ. 2006, 40, 6181.

64. Mariani, R. L.; de Mello, W. Z.; Atmos. Environ. 2007, 41, 2887. 
65. Soluri, D. S.; Godoy, M. L. D. P.; Godoy, J. M.; Roldão, L. A.; J. Braz. Chem. Soc. 2007, 18, 838.

66. Godoy, M. L. D. P.; Godoy, J. M.; Roldão, L. A.; Soluri, D. S.; Donagemma, R. A.; Atmos. Environ. 2009, 43, 2366.

67. Toledo, V. E.; Almeida, P. B.; Quiterio, S. L.; Arbilla, G.; Moreira, A.; Escaleira, V.; Moreira, J. C.; Environ. Monit. Assess. 2008, 139, 49.

68. WHO; Air quality guidelines for particulate matter, ozone, nitrogen dioxide and sulfur dioxide; Genebra, 2005.

69. USEPA; Reviewing National Ambient Air Quality Standards (NAAQS): Scientific and Technical Information, Table of current NAAQS, disponível em https://www.epa.gov/criteria-air-pollutants/naaqs-table, acessada em fevereiro 2021.

70. DG Environment Standards Air Quality Standards, disponível em https://ec.europa.eu/environment/air/quality/standards.htm, acessada em fevereiro 2021.

71. Resolução CONAMA No3/90 de 28 de junho de 1990; Brasil, 1990; p. 5.

72. CONAMA Resolução $n^{\circ} 491 / 18$ de 18 de novembro de 2018; Brasil, 2018; p. 7.

73. IEMA; Qualidade do Ar, disponível em http://energiaeambiente.org.br/ produto/1o-diagnostico-da-rede-de-monitoramento-da-qualidade-do-arno-brasil, acessada em fevereiro 2021.

74. Quijano, M. F. C.; Mateus, V. L.; Saint'Pierre, T. D.; Bott, I. S.; Gioda, A.; Microchem. J. 2019, 147, 507.

75. Justo, E.; Quijano, M. F.; Beringui, K.; Saint'Pierre, T.; Gioda, A.; J. Braz. Chem. Soc. 2020, 31, 1043.

76. Loyola, J.; De Almeida, P. B.; Quiterio, S. L.; Sousa, C. R.; Arbilla, G.; Escaleira, V.; De Carvalho, M. I.; Da Silva, A. D. S. A. G.; Arch. Environ. Contam. Toxicol. 2006, 51, 485.

77. Quiterio, S. L.; Arbilla, G.; Escaleira, V.; Silva, C. R. S.; Wasserman, M. A.; Bull. Environ. Contam. Toxicol. 2006, 77, 119.

78. Loyola, J.; Arbilla, G.; Quiterio, S. L.; Escaleira, V.; Bellido, A. V.; J. Braz. Chem. Soc. 2009, 20, 1343.

79. de Miranda, R. M.; de Fatima Andrade, M.; Fornaro, A.; Astolfo, R.; de Andre, P. A.; Saldiva, P.; Air Qual. Atmos. Heal. 2012, 5, 63.

80. de Rainho, C. R.; Corrêa, S. M.; Mazzei, J. L.; Aiub, C. A. F.; Felzenszwalb, I.; Biomed Res Int. (2013).

81. Ventura, L. M. B.; Mateus, V. L.; de Almeida, A. C. S. L.; Wanderley, K. B.; Taira, F. T.; Saint'Pierre, T. D.; Gioda, A.; Air Qual. Atmos. Heal. 2017, 10, 845

82. De Almeida Azevedo, D.; Dos Santos, C. Y. M.; De Aquino Neto, F. R.; Atmos. Environ. 2002, 36, 2383.

83. Azevedo, H. D. A.; Moreira, L. S. 1999, 33.

84. Rainho, C. R.; Corrêa, S. M.; Mazzei, J. L.; Aiub, C. A. F.; Felzenszwalb, I.; WIT Trans. Ecol. Environ. 2014, 183, 87.

85. Mateus, V. L.; Gioda, A.; Marinho, H. R.; Rocha, R. C. C.; Valles, T. V.; I. Prohmann, A. C.; dos Santos, L. C.; Oliveira, T. B.; Melo, F. M.; Saint'Pierre, T. D.; P.G. Maia, L. F.; Urban For. Urban Green. 2020, 56 , 126858.

86. Hopke, P. K.; Xie, Y.; Raunemaa, T.; Biegalski, S.; Landsberger, S.; Artaxo, P.; Cohen, D.; Aerosol Sci. Technol. 1997, 27, 726.

87. Brook, J. R.; Dann, T. F.; Burnett, R. T.; J. Air Waste Manage. Assoc. 1997, 47, 2.

88. Ventura, L. M. B.; Ramos, M. B.; Santos, J. O.; Gioda, A.; An. Acad. Bras. Cienc. 2019, 91, 1 .

89. De La Cruz, A. R. H.; Dionisio Calderon, E. R.; França, B. B.; Réquia, W. J.; Gioda, A.; Atmos. Environ. 2019, 203, 206.

90. De La Cruz, A. R. H.; Dionisio Calderon, E. R.; França, B. B.; Réquia, W. J.; Gioda, A.; Atmos. Environ. 2019, 203, 206.

91. Bezerra, C. A.; De Carvalho, N. J.; Geraldino, C. G. P.; Da Silva, C. M.; Arbilla, G.; J. Braz. Chem. Soc. 2018, 29, 2220.

92. Tsuruta, F.; Carvalho, N. J.; Silva, C. M.; Arbilla, G.; J. Braz. Chem. Soc. 2018, 29, 1291.
93. Quiterio, S. L.; Loyola, J.; Almeida, P. B.; Viviane, V.; Arbilla, G.; Bull. Environ. Contam. Toxicol. 2006, 77, 651.

94. Dos Anjos Paulino, S.; Oliveira, R. L.; Loyola, J.; Minho, A. S.; Arbilla, G.; Quiterio, S. L.; Escaleira, V.; Bull. Environ. Contam. Toxicol. 2014, 92, 590.

95. MMA; Inventário Nacional de Emissões Atmosféricas por Veículos Automotores Rodoviários, 2014, 115.

96. Detran; Estatísticas, disponível em http://www.detran.rj.gov.br/_ estatisticas.veiculos/index.asp, acessada em fevereiro 2021.

97. Jaconis, S. Y.; Culley, T. M.; Meier, A. M.; Environ. Pollut. 2017, 222, 261.

98. Santos, T. C.; Carvalho, V. S. B.; Reboita, M. S.; Eng. Sanit. e Ambient. 2016, 21, 307.

99. Souza, M. L.; Allen, A. G.; Cardoso, A. A.; Atmos. Res. 2017, 183, 94.

100. USEPA Compendium Method IO-3.1, Selection, preparation and extraction of filter material, Cent. Environ. Res. Inf. Off. Res. Dev. US Environ. Prot. Agency 1999, 1-30.

101. Gioda, A.; Reyes-Rodríguez, G. J.; Santos-Figueroa, G.; Collett, J. L.; Decesari, S.; Ramos, M. D. C. K. V.; Bezerra Netto, H. J. C.; De Aquino Neto, F. R.; Mayol-Bracero, O. L.; J. Geophys. Res. Atmos. 2011, 116.

102. Marrero, J.; Rebagliati, R. J.; Gómez, D.; Smichowski, P.; Talanta 2005, $68,442$.

103. Ventura, L. M. B.; Amaral, B. S.; Wanderley, K. B.; Godoy, J. M.; Gioda, A.; J. Braz. Chem. Soc. 2014, 25, 1571.

104. Rodríguez-Cotto, R. I.; Ortiz-Martínez, M. G.; Rivera-Ramírez, E.; Mateus, V. L.; Amaral, B. S.; Jiménez-Vélez, B. D.; Gioda, A.; Environ. Pollut. 2014, 194, 112.

105. USEPA USEPA Method 300.1, Determination of inorganic anions in drinking water by ion chromatography 1997, 0-39.

106. Salcedo, D.; Bernal, J. P.; Pérez-Arvizu, O.; Lounejeva, E.; J. Anal. At. Spectrom. 2014, 29, 753.

107. Steverlynck, L.; Baert, N.; Buylaert, W.; De Paepe, P.; Acta Clin. Belgica Int. J. Clin. Lab. Med. 2017, 72, 278.

108. Bajraktarova-Valjakova, E.; Korunoska-Stevkovska, V.; Georgieva, S.; Ivanovski, K.; Bajraktarova-Misevska, C.; Mijoska, A.; Grozdanov, A.; Open Access Macedonian Journal of Medical Sciences 2018, 6, 2257.

109. Ventura, L. M. B.; de Oliveira Pinto, F.; Soares, L. M.; Luna, A. S.; Gioda, A.; Air Qual. Atmos. Heal. 2019, 12, 317.

110. Soluri, D. S.; Tese de Doutorado, Pontifícia Universidade Católica do Rio de Janeiro, Brasil, 2005.

111. Olmez, I.; Cetin Gulovali, M.; Gordon, G. E.; Atmos. Environ. 1985, 19, 1663.

112. Çevik, F.; Göksu, M. Z. L.; Derici, O. B.; Findik, Ö.; Environ. Monit. Assess. 2009, 152, 309

113. Elhadi, R. E.; Abdullah, A. M.; Abdullah, A. H.; Ash'Aari, Z. H.; Khan, M. F.; Aerosol Air Qual. Res. 2018, 18, 1148.

114. Hien, P. D.; Binh, N. T.; Truong, Y.; Ngo, N. T.; Sieu, L. N.; Atmos. Environ. 2001, 35, 2669.

115. Wu, X.; Deng, J.; Chen, J.; Hong, Y.; Xu, L.; Yin, L.; Du, W.; Hong, Z.; Dai, N.; Yuan, C. S.; Aerosol Air Qual. Res. 2017, 17, 2152.

116. Ren, L.; Wang, W.; Wang, Q.; Yang, X. Y.; Tang, D.; Atmos. Environ. 2011, 45, 7503.

117. Masiol, M.; Squizzato, S.; Ceccato, D.; Pavoni, B.; Chemosphere 2015, $119,400$.

118. Pernigotti, D.; Belis, C. A.; Spanó, L.; Atmos. Pollut. Res. 2016, 7, 307.

119. Pant, P.; Harrison, R. M.; Atmos. Environ. 2013, 77, 78.

120. Zhao, Y.; Wang, P.; Ma, L.; Yan, H.; Procedia Eng. 2017, 205, 1331.

121. de Fatima Andrade, M.; de Miranda, R. M.; Fornaro, A.; Kerr, A.; Oyama, B.; de Andre, P. A.; Saldiva, P.; Air Qual. Atmos. Heal. 2012, 5 , 79.

122. Mamane, Y.; Mehler, M.; Atmos. Environ. 1987, 21, 1989.

123. Keck, L.; Wittmaack, K.; Atmos. Environ. 2005, 39, 4093. 